NBER WORKING PAPER SERIES

\title{
PAYING OFF THE COMPETITION: MARKET POWER AND INNOVATION INCENTIVES
}

\author{
Xuelin Li \\ Andrew W. Lo \\ Richard T. Thakor \\ Working Paper 28964 \\ http://www.nber.org/papers/w28964 \\ NATIONAL BUREAU OF ECONOMIC RESEARCH \\ 1050 Massachusetts Avenue \\ Cambridge, MA 02138 \\ June 2021
}

We thank Jan Bena (discussant), Chirantan Chatterjee, Greg Glass, Matt Higgins, Josh Krieger, Howard Kung (discussant), Filippo Mezzanotti, Myles Shaver, and participants at the Minnesota Corporate Finance Conference and SFS Cavalcade North America for helpful comments and suggestions. We also thank Matt Higgins for providing data. We thank Xuan Xie, Anushka Ray, Paula Fenstad, and Paul Freed for research assistance. Any errors are our own. Research support from the MIT Laboratory for Financial Engineering is gratefully acknowledged. The views expressed herein are those of the authors and do not necessarily reflect the views of the National Bureau of Economic Research.

NBER working papers are circulated for discussion and comment purposes. They have not been peer-reviewed or been subject to the review by the NBER Board of Directors that accompanies official NBER publications.

(C) 2021 by Xuelin Li, Andrew W. Lo, and Richard T. Thakor. All rights reserved. Short sections of text, not to exceed two paragraphs, may be quoted without explicit permission provided that full credit, including $\odot$ notice, is given to the source. 
Paying off the Competition: Market Power and Innovation Incentives

Xuelin Li, Andrew W. Lo, and Richard T. Thakor

NBER Working Paper No. 28964

June 2021

JEL No. D42,D43,G31,K21,L41,L43,L65,O31,O32

\begin{abstract}
How does a firm's market power in existing products affect its incentives to innovate? We explore this fundamental question using granular project-level and firm-level data from the pharmaceutical industry, focusing on a particular mechanism through which incumbent firms maintain their market power: "reverse payment" or "pay-for-delay" agreements to delay the market entry of competitors. We first show that when firms are unfettered in their use of "payfor-delay" agreements, they reduce their innovation activities in response to the potential entry of direct competitors. We then examine a legal ruling that subjected these agreements to antitrust litigation, thereby reducing the incentive to enter them. After the ruling, incumbent firms increased their net innovation activities in response to competitive entry. These effects center on firms with products that are more directly affected by competition. However, at the product therapeutic area level, we find a reduction in innovation by new entrants after the ruling in response to increased competition. Overall, these results are consistent with firms having reduced incentives to innovate when they are able to maintain their market power, highlighting a specific channel through which this occurs.
\end{abstract}

Xuelin Li

University of South Carolina

1014 Greene St

Columbia, SC 29208

xuelin.li@moore.sc.edu

Andrew W. Lo

MIT Sloan School of Management

100 Main Street, E62-618

Cambridge, MA 02142

and NBER

alo-admin@mit.edu
Richard T. Thakor

University of Minnesota,

321 19th Avenue South, 3-255

Minneapolis, MN 5545

rthakor@umn.edu 


\section{Introduction}

The effect of competition among firms on innovation is a critical issue for policymakers, given the importance of innovation as a driver of economic growth. However, the relationship between increased competition and innovation is not clear-cut in the literature (e.g. Aghion, Bloom, Blundell, Griffith, and Howitt (2005)). On the one hand, measures such as greater patent protection to reward firms for innovation by limiting competition may encourage further innovation in order to reap monopoly profits. On the other hand, an incumbent firm with an existing product under such protection may feel no need to innovate further if it can already rely on a guaranteed revenue stream from the product. Understanding the interaction between these forces is crucial for ascertaining the effect of policies aimed at increasing innovation by changing the degree of competition in a market, such as antitrust enforcement and patent policy.

In this paper, we explore this issue by providing evidence from a legal mechanism through which innovative firms may maintain their market power, and its ramifications for innovation. We do so in the setting of a particular sector known for developing innovative products through its research and development (R\&D) activities-the pharmaceutical industry. In this industry, firms that are first to pass clinical trials and obtain Food and Drug Administration (FDA) approval for their drugs enjoy marketing exclusivity for a number of years, during which no other firm can directly compete against that drug. However, after marketing exclusivity expires, other firms may enter the market by launching generic versions of the specific drug through what is known as a Paragraph IV filing. In order to continue their monopoly over marketed drugs, incumbent pharmaceutical firms have regularly entered into "pay-for-delay" agreements-also known as "reverse payments" - settlements with entering generic 
manufacturers, whereby the generic firm agrees to delay product launch in exchange for a cash amount. These agreements effectively provide an endogenous tool through which incumbent firms can reduce the competition that they face.

Using detailed data on public pharmaceutical firms and their drug development portfolios from 2005 to 2016, we construct a firm-specific measure of the amount of competition that each incumbent faces through Paragraph IV generic drug entry filings. We show that unconditionally over our sample period, incumbent firms responded to potential entry from direct competitors by reducing their innovation activity and initiating a smaller number of new drug trials. ${ }^{1}$ The results suggest that firms appear to reduce their levels of innovation when faced with increased competition.

We then explore the effect of a Supreme Court ruling in 2013, FTC v. Actavis, which increased the legal risk of engaging in pay-for-delay agreements. The ruling stated that under antitrust law, the Federal Trade Commission (FTC) could target such agreements, and granted the FTC broader bargaining power in these types of antitrust settlements. Consistent with the increased legal risk, we document a sharp decline in the number of pay-for-delay agreements after the ruling, a stark reversal of the previous trend. Furthermore, we show that the ruling did not appear to change the incentives of generic entrants, which filed at the same rate both before and after the ruling. ${ }^{2}$ We therefore interpret the ruling as an unexpected regulatory change that reduced the ability of incumbent firms to enter into agreements to impede new competition.

\footnotetext{
${ }^{1}$ As we discuss in the paper, our setting affords us to measure real innovation activity through project decisions, rather than having to rely on measures such as patents, which may not correspond to actual innovation (see, e.g. Kelly (1990) and Freilich (2018)).

2 This supports the view that generic firms did not enter for the purpose of engaging in pay-for-delay settlements; put differently, these firms enter into a market because it would be profitable to compete against the branded (incumbent) drugs.
} 
Our initial result, that incumbent firms reduce their levels of innovation when faced with increased competition, reverses itself following this ruling. Put differently, pharma firms after the ruling increase their number of new drug trial initiations and decrease their number of suspensions of existing projects in response to generic entry filings. This suggests that the initial negative relationship between generic competition and innovation is driven primarily by the ability of incumbent firms to protect their monopoly power through pay-for-delay agreements. Such agreements allow firms to resolve the uncertainty of product competition and reduce the need to maintain their competitive edge with novel drugs. However, after this channel becomes legally risky, firms need to rely on innovation activities to escape neck-and-neck competition (e.g. Aghion et al. (2005)).

While the above results are suggestive, they are subject to concerns about endogeneity and reverse causality, since generic entry and signing pay-for-delay agreements are contemporaneously endogenous decisions made by both incumbents and entrants. In order to address these concerns, we use the FTC v. Actavis ruling as a natural experiment, and conduct a differences-in-differences (diff-in-diff) analysis by exploiting firm heterogeneity in their exposure to the ruling. Specifically, incumbent firms with drugs slated to lose marketing exclusivity in the years immediately following the ruling had increased exposure to generic entry, and thus, to the court ruling. Furthermore, since the expiration date of marketing exclusivity for these drugs had been predetermined at the end of the drug approval process, which spans a number of years (e.g. DiMasi and Grabowski (2007)), the institutional framework alleviates concerns of self-selection into the treatment group. This diff-in-diff analysis shows that exposed firms had a relative increase in innovation through a higher number of new trial initiations, a lower number of suspensions. We additionally provide evidence that the economic value of new 
innovations increases by relatively more for exposed firms, consistent with an increase in effort by developing firms that resulted in higher-quality innovation.

We validate these results through a number of robustness checks. First, we replicate the same exercise at the firm-therapeutic-category level and document that these effects also hold both across different categories within a single firm as well as across different firms within a single category. ${ }^{3}$ Second, our identification strategy requires that the loss of market exclusivity significantly increases innovation activities only after FTC $v$. Actavis. To show this, we perform a placebo test by counterfactually assuming the ruling occurred in 2009, and using firms with drug exclusivities expiring between 2009 and 2012 as the pseudo-treatment group. We obtain no significant results via this test for our outcome variables.

We also document a number of other results that are consistent with the diminished ability of firms to engage in pay-for-delay driving these effects. First, using data on drug sales, we find that these effects are centered on two groups: firms that have drugs with high sales whose exclusivity was set to expire after the Supreme Court ruling, and firms with a large number of drugs whose exclusivities were set to expire after the ruling. Both of these effects are consistent with the hypothesized responses of firms that are the most affected by the law. Second, we find that the affected firms are more likely to acquire projects from other firms, which is consistent with firms choosing to in-source existing projects from other firms as an alternative to in-house innovation. Third, we find that the affected firms increased their R\&D expenditures and decreased their cash holdings following the ruling, which is consistent with firms spending to expand their net

\footnotetext{
${ }^{3}$ A therapeutic category is a group of indications sharing high pathological correlations. Drugs aimed at a specific category are plausibly close substitutes and hence close competitors. We follow the Center for Medicare \& Medicated Services' ICD-10 medical classification assessment and group diseases in the same subchapter level as the therapeutic category.
} 
innovation activities. Finally, we use hand-collected data from 10-K filings and searches of news articles to find mentions of litigation faced by incumbent companies. We show that patent infringement settlements went down after the Supreme Court ruling. In contrast, the number of litigated court cases with rulings and the number of rulings where generic drugs were allowed to enter (i.e. cases that are not settled) went up. These effects are consistent with the hypothesized effects of the original FTC $v$. Actavis ruling.

In the final part of our analysis, we explore the overall impact on innovations within a therapeutic category, in order to examine effects at the extensive margin and estimate the aggregation effects of individual firm decisions. At the level of therapeutic category, we find an overall decrease in suspensions as well as an increase in new trial initiations by incumbent firms exposed to competition risk by the Supreme Court ruling. However, we also find that the enhanced ability of generic producers to enter an area may dampen entry into the area by new firms. This suggests that the ability of incumbent firms to stave off generic competition has implications not only for the decision to innovate by incumbents but also for the decision to innovate by new (non-generic) potential innovators. Our results are consistent with theories predicting that the effect of antitrust policy on innovation is not clear-cut, e.g. Segal and Whinston (2007), but our results shed new light on the reasons for this, and imply that the effects of optimal policy related to antitrust law on innovation will be nuanced.

This paper is related to the broad theoretical and empirical literature that explores the relationship between competition and innovation: see Tirole (1988), Aghion, Harris, Howitt, and Vickers (2001), Aghion, Bloom, Blundell, Griffith, and Howitt (2005), Gans, Hsu, and Stern (2002), Gans and Stern (2003a), among many others; Ahn (2002) provides a review of the literature. Also related is the literature on the optimal design of a property rights system with respect to innovation incentives (e.g. Klemperer (1990), Gilbert and 
Shapiro (1990), Hopenhayn, Llobet, and Mitchell (2006), Acemoglu and Akcigit (2012), and Williams (2013), among others). Our paper contributes to these strands of the literature by providing evidence that the relationship between competition and innovation can depend on the tools available to incumbent firms within the property rights and antitrust law system. Specifically, our results indicate that increased competition leads to reduced innovation as long as incumbents have access to tools to keep competition at bay, but it increases innovation once these tools have either been exhausted or are otherwise unavailable. However, this increase in innovation at the intensive margin is accompanied by a possible decline in innovation at the extensive margin.

Our paper is directly connected to the literature that explores competitive effects in the biopharmaceutical industry, particularly with regard to the effect of generic manufacturers on incumbent firms. Higgins and Graham (2009) argue that generic penetration carries a long-term growth concern for the ex ante R\&D incentives of incumbent firms. Branstetter, Chatterjee, and Higgins (2016) examine the welfare consequences of Paragraph IV generic entry in the pharmaceutical industry and estimate that generics increase consumer surplus but reduce producer surplus. Thakor and Lo (forthcoming) explore the effect of increased competition in the biopharmaceutical industry induced by easier generic entry through the Hatch-Waxman Act, finding that affected firms increased their R\&D but decreased their levels of innovation (measured through patents). ${ }^{4}$ Branstetter, Chatterjee, and Higgins (2014) estimate the effect of generic entry on incentives for early-stage pharmaceutical innovation and find that an

\footnotetext{
${ }^{4}$ Grabowski and Vernon (1992) examines market share and entry for a sample of drugs following the enactment of the Hatch-Waxman Act, and demonstrates that generic entry does significantly increase competition for incumbent producers. Grabowski (2007) provides an overview.
} 
increase in generic penetration reduces early-stage innovation in therapeutic markets. Garfinkel and Hammoudeh (2020) use FDA breakthrough designation therapy indications as a shock to pharmaceutical competition and find evidence consistent with such shocks discouraging rivals' innovation in an area along the lines of Aghion et al. (2005).

Our paper also examines the effect of generic entry on pharmaceutical innovation, but it highlights the importance of the legal environment in mediating the relationship between generic competition and innovation. Like these earlier papers, we also find a negative relationship between generic entry and innovation, but we have the novel finding that this relationship is driven by the ability of incumbents to engage in pay-fordelay settlements with generic entrants. In particular, we document a reversal of this result when pay-for-delay agreements are impeded.

The remainder of this paper is organized as follows. In Section 2, we provide a brief theoretical framework to motivate our analysis. Section 3 describe the institutional background related to the pharmaceutical industry, generic entry, and the FTC v. Actavis ruling. Section 4 describes our data sources. Section 5 describes our empirical methodology and provides results for our Paragraph IV panel regressions. Section 6 contains our diff-in-diff methodology and results. Section 7 examines the aggregated effects at the level of therapeutic area. Section 8 concludes.

\section{Conceptual Framework}

In this section, we briefly describe a simple theoretical framework to guide our hypotheses and empirical analysis. The framework is based on the models of Corhay, 
Kung, and Schmid (2020, 2021), which examine the relationship between innovation and competition. ${ }^{5}$

Consider a setting where $N_{t}$ drug development firms operate at time $t$. Each firm $i$ produces drug products $X_{i, t}$ with a cost function of $C_{\mathrm{i}, \mathrm{t}}=C\left(X_{\mathrm{i}, \mathrm{t}}\right)$, where $C_{\mathrm{i}, \mathrm{t}}=C^{\prime}\left(X_{\mathrm{i}, \mathrm{t}}\right)>0$, and $C^{\prime \prime}\left(X_{i, t}\right)>0.6$ This implies that a firm's marginal profit decreases with additional drugs. Consider a constant elasticity substitution (CES) demand system for a particular class of drugs at time $t$, denoted by $Q_{t}$ :

$$
Q_{t}=\left[\sum_{i=1}^{N_{t}} X_{i, t} \frac{v-1}{v}\right]^{\frac{v}{1-v}} .
$$

where $v$ is the elasticity of substitution. Firms behave as oligopolists, and internalize the impact of their price strategies on demand. Due to competitive interactions between firms, markups are a function of competition, $\varphi\left(N_{t}\right)$. There is a negative relationship between markups and competition, $\varphi^{\prime}\left(N_{t}\right)<0$, since a greater number of firms will lead to a more elastic demand for products. In a symmetric equilibrium, denote the total discounted (stochastic) future payoffs for firms at time $t$ as $V_{t}$. The cost function and demand system imply that $V_{t}$ decreases with $N_{t}$.

Now consider the impact of entry by generic drug manufacturing firms. We can view the free entry condition for generic firms as a function of the exogenous cost to set up a new firm $\chi$, the probability of the generic drug being approved $q$, and the stochastic discount factor $M_{t+1}$ :

$$
\chi=q \mathbb{E}\left[M_{t+1} V_{t+1}\right]
$$

\footnotetext{
${ }^{5}$ We thank Howard Kung for his suggestions regarding this framework.

${ }^{6}$ In a fully specified model, $X_{i, t}$ can also be specified to be a function of physical capital, intangible capital, and labor inputs, where $C_{\mathrm{i}, \mathrm{t}}=C\left(X_{\mathrm{i}, \mathrm{t}}\right)$ represents the costs of input. See Corhay, Kung, and Schmid (2020, 2021).
} 
Intuitively, an exogenous decrease in the cost $\chi$ or an increase in the approval probability $q$ will result in higher entry and a lower $\varphi\left(N_{t}\right)$ in equilibrium.

Suppose that incumbent firms can decrease the approval probability $q$ through either innovation investment $Z_{t}$ or strategic settlement (pay-for-delay) agreements $D_{t}$, i.e., $q_{t}=$ $q\left(Z_{t}, D_{t}\right)$. Innovation investment can generate novel products and reward incumbents with additional marketing exclusivities, making generic approvals infeasible. Thus, $\partial q_{t} / \partial Z_{t}<0$, which echoes the "escape the competition" incentive for innovation reflected in the literature. Similarly, strategic settlements delay the actual timing of product launch, i.e., $\partial q_{t} / \partial D_{t}<0$.

This setup implies that we can write $V_{t}$ as a function of $q_{t}$. When incumbent firms can freely use pay-for-delay schemes after a potential generic manufacturer enters, the incumbent will utilize both innovation investment $Z_{t}$ and pay-for-delay settlements $D_{t}$ to reduce $q_{t}$. In equilibrium, the optimal levels of $Z_{t}$ and $D_{t}$ will be determined such that the marginal benefits are equal to the marginal costs. ${ }^{7}$ Therefore, the effectiveness of pay-fordelay settlements dampens the incentive for incumbent firms to innovate in response to the entry of a generic firm. However, when pay-for-delay schemes are made less viable (e.g., as $\partial q_{t} / \partial D_{t}$ goes down), then the "escape the competition" effect dominates, and increased innovation is the most viable way to increase barriers to entry.

This framework thus provides the following predictions:

1) With the ability to use pay-for-delay schemes, incumbent firms will allocate resources away from innovation and towards pay-for-delay.

\footnotetext{
${ }^{7}$ Denote the convex and increasing cost functions for $Z_{t}$ and $D_{t}$ as $S\left(Z_{t}\right)$ and $R\left(D_{t}\right)$, respectively. Then the optimal investments in $Z_{t}$ and $D_{t}$ are determined by the following first order conditions: $\frac{\partial V_{t}}{\partial q_{t}} \frac{\partial q_{t}}{\partial Z_{t}}-S^{\prime}\left(Z_{t}\right)=0, \quad \frac{\partial V_{t}}{\partial q_{t}} \frac{\partial q_{t}}{\partial D_{t}}-R^{\prime}\left(D_{t}\right)=0$
} 
2) When the effectiveness of pay-for-delay schemes is diminished, firms will shift to more investment in innovation at the margin.

\section{Institutional Setting}

In this section, we review the institutional setting related to generic entry in the pharmaceutical industry, as well as the FTC v. Actavis court ruling.

\subsection{Generic Entry in the Pharmaceutical Industry}

The current regulatory regime in the pharmaceutical industry for generic and brandname drugs is a consequence of the passage of the Hatch-Waxman Act of 1984. Intended to benefit consumers by increasing drug choices through competition, this legislation dramatically changed the terms under which a generic product could be approved in the same market as an existing branded drug. Prior to the enactment of this law, the FDA required generic drugs to replicate much of the original clinical trial testing in order to gain market approval, resulting in significant development costs. After the passage of the Hatch-Waxman Act, these restrictions were eased, and generic developers only needed to prove bioequivalence to the original drug (i.e. that the generic delivers the same clinical benefit), thus allowing generic manufacturers to by pass portions of the drug trial process. The Hatch-Waxman Act also introduced a provision whereby generic producers could more easily challenge the patent protection of brand-name drugs once their marketing exclusivity had expired. Overall, this facilitated the increased entry of generic products 
in drug markets and allowed them to provide low-cost substitutes for consumers, exposing incumbent producers to significantly higher levels of competition. ${ }^{8}$

Under the provisions of the Hatch-Waxman Act, the timing of generic entry depends on the marketing exclusivity and patent protection of a new drug. A developing firm will typically first apply for a patent early in the drug trial process. Generally, the term of each patent will last about 20 years from its application. If a drug survives clinical trialstypically lasting 8 years (e.g. DiMasi and Grabowski (2007)) - the firm will submit a New Drug Application (NDA) to the FDA in order to gain approval to market the drug to consumers. If the drug is approved, the FDA will grant exclusive marketing rights to the new product, meaning that no generic producer can apply for a competing product. The length of exclusivity typically lasts 3 to 7 years. As described in more detail below, marketing exclusivity endows the recipient with monopoly power, and it is much stronger than patent protection.

Under Hatch-Waxman, a generic manufacturer must file an Abbreviated New Drug Application (ANDA) with one of four Paragraph certifications when seeking generic approval. Each Paragraph certification corresponds to different conditions of patent availability and expiration. Among them, only Paragraph IV (Para-IV) certification applies to the case when a branded product's patent has not expired. By filing a Para-IV entry certification, the generic maker declares that its product does not infringe on a patent or that patent is invalid. Figure 1 illustrates the timeline of generic entry during a brand-name drug's post-approval lifespan.

[Figure 1 here]

\footnotetext{
8 See Grabowski $(2004,2007)$ and Thakor and Lo (forthcoming) for details of the provisions and the law, and evidence of its effect on pharmaceutical competition. Berndt and Aitken (2011) show that generic entry is economically important in the industry, while Reiffen and Ward (2005) provide evidence that generics dramatically decrease the market share of brand pioneers.
} 
After being notified of a Para-IV ANDA, an incumbent pharmaceutical company often sues the generic maker for patent infringement. This litigation process is beneficial for the brand-name owner. It triggers an automatic 30-month stay on the FDA's approval of the generic drug - the FDA may only approve the ANDA upon the first court ruling in favor of the manufacturer, or if a settlement is reached. Once the generic is approved to enter into the market, it is awarded 180 days of market exclusivity as the sole generic provider in competition with the branded drug. ${ }^{9}$

Following the initiation of litigation, the incumbent drug owner often seeks a settlement before the court decision. This is not only because litigation is costly and timeconsuming, but also because the courts usually rule in favor of the generic application. ${ }^{10}$ If the brand-name and generic manufacturers enter into a settlement, it may specify the generic product's time of entry into the market, as well as the royalties owed by the generic manufacturer. However, the brand-name producer may instead choose to settle with the generic manufacturer by offering a direct payment through a "pay-for-delay" agreement. ${ }^{11}$ In exchange, a generic manufacturer agrees to refrain from entering the market for an additional amount of time. ${ }^{12}$

As an example, several generic drug makers filed ANDAs that threatened the exclusivity of the drug Androgel in 2003. Androgel's owner, Solvay Pharmaceuticals, ${ }^{13}$

\footnotetext{
${ }^{9}$ If the generic manufacturer loses its Para-IV case, it then de facto becomes a Paragraph III filing, in which case the applicant agrees to wait until the relevant patent expires before it seeks final ANDA approval. ${ }_{10}$ An FTC study (FTC (2002)) documents that generic applications prevailed in $73 \%$ of the patent litigations that were ultimately resolved by a court decision from 1992 to June 2002.

11 The FTC considers a variety of non-pecuniary exchanges to be equivalent to payments. For example, the aforementioned 180-day market exclusivity of first filer does not apply to the brand-name pharmaceutical company's "authorized generic" or "AG". An incumbent company could postpone entry by promising not to launch an AG and erode a generic product's profits.

12 An FTC study in 2010 (FTC (2010)) indicates that "agreements with compensation on average prohibit generic entry for nearly 17 months longer than agreements without payments". Consistent with these agreements being collusive, Helland and Seabury (2016) document that Para-IV challenges lower drug prices and increase quantity, but the effect is reversed if a settlement is reached.

13 Solvay was later acquired by Abbott Laboratories and is now owned by AbbVie Inc. after being spun off.
} 
sued the generic companies for patent infringement, but the litigation process exceeded the FDA's 30-month stay and Actavis Inc. (formerly Watson Pharmaceuticals) had its generic version approved in January 2006. In September 2006, Solvay persuaded Actavis to delay its product launch until 2015, and in the meantime to help promote Androgel. In exchange, Solvay made annual payments of $\$ 19$ to 30 million to Actavis for "promotion costs."

\subsection{The FTC v. Actavis Ruling}

Pay-for-delay agreements were a commonly used strategy in the 2000s (see Bulow (2004)). In the early 2010s, the Federal Trade Commission (FTC) argued that pay-fordelay agreements effectively allowed brand-name producers and generic manufacturers to form a cartel that enabled them to share a monopolistic market profit. This eventually led to the landmark decision FTC v. Actavis in 2013, in which the Supreme Court held that the FTC could litigate pay-for-delay agreements under antitrust law. ${ }^{14}$ This decision was arguably unexpected, since prior to the ruling, both the District Court and Eleventh Circuit Court dismissed the FTC's claims, while the final Supreme Court decision was split 5-to-3.

Since the ruling, the FTC has aggressively targeted pay-for-delay agreements. It has successfully sued a number of pharmaceutical firms for non-cash delay strategies, such as promising no authorized generic (AG) launches or providing other first generic arrangements. The FTC $v$. Actavis ruling also granted more bargaining leverage to the FTC. For example, in addition to $\$ 1.2$ billion in monetary relief to compensate drug buyers, Cephalon Inc. and Teva Pharmaceutical agreed to a prohibition on entering any

\footnotetext{
${ }_{14}$ No. 12-416, 570 U.S. _ (2013). While the ruling did not ban pay-for-delay agreements, it made clear that such agreements could fall under the FTC's antitrust regulatory powers under rule of reason, thus making them much more legally tenuous.
} 
kind of future pay-for-delay deals in a 2015 FTC settlement. Firms now incur a substantial increase in legal risk stemming from antitrust enforcement if they have engaged in payfor-delay agreements after this ruling.

As evidence for the effect of the ruling, Table 1 summarizes the yearly number of drugs with first Para-IV generic filers, final settlements, and pay-for-delay agreements. ${ }^{15}$ As the table shows, the FTC $v$. Actavis ruling did not change the intensity of Para-IV first filings - the number of Para-IV filings remains flat around the ruling. This suggests that the ruling did not change the decisions of generic producers to enter into the marketplace. Put differently, generic producers are likely not entering solely to engage in pay-for-delay agreements, but rather are entering the market because it is profitable to do so.

[Table 1 Here]

In contrast, pay-for-delay agreements drop sharply after the ruling. This is also seen graphically in Figure 2. In the years leading up to 2013, the number of pay-for-delay settlements showed a strong increasing trend. However, after 2013, this trend reverses itself. This effect holds when including all pay-for-delay agreements, as well as only agreements with generic first filers (the first generic company to file for Para-IV entry). For example, in 2015, there were only 7 settlements with first filers, the lowest number since 2006.

[Figure 2 Here]

\footnotetext{
15 The aggregated data come from the FTC's annual report on Medicare Modernization Act Agreement Filings.
} 


\section{Data Description}

Our analysis is based on a sample of public firms in the pharmaceutical and biotechnology industries. We first extract detailed firm-specific drug development and trial information from an industry competitive intelligence database. We then construct financial variables for these firms through the Compustat database. We supplement this sample with additional data on Para-IV certification filings and updates on exclusivity and litigation efforts.

\subsection{Drug Development Data}

Our main data come from the BioMedTracker (BMT) database, an industry competitive intelligence database that covers drug trial information in detail for the universe of public and private biopharmaceutical companies in the U.S. For each firm, the database contains pipeline development history dating as far back as the 1980s (although the coverage is more complete after 2000). In pharmaceutical development, drugs target the specific symptoms of a disease, known medically as indications. Since each drug may potentially apply to multiple indications, and thus may be approved by the FDA at different times, trial information is subdivided at the indication level. We therefore define each combination of drug and indication as a project.

The FDA drug development approval process consists of three clinical trial phasesphase 1,2, and 3-and a final NDA/BLA (new drug application/biologic license application) FDA approval phase. In the BMT database, the history for each project covers events across all of these phases, including drug trial initiation, phase trial updates, trial suspensions, regulatory information, marketing decisions, partnerships, acquisitions,

and patent updates. Upon each event, the database also includes the phase of the FDA approval process for the indication, and the likelihood of its eventual approval, calculated 
using a combination of historical data and analyst estimates. Given each firm's research portfolio, defined as the set of ongoing projects, we include its size (the total number of ongoing projects) and the average probability of final approval as control variables.

We examine a variety of outcome variables to characterize detailed project choice decisions by biopharma firms. For each firm, we explore the number of projects it initiates and suspends. Since innovative sectors like the biopharma industry are characterized by an active market for ideas (e.g. Gans and Stern $(2003 a, b))$, in which firms frequently acquire R\&D-related assets from each other, we also construct a variable that tracks the external projects acquired by each firm.

For our analysis of the litigation process, we also look at the number of drugs associated with patent infringement settlements. Finally, for the aggregate analysis of the impact on competition in a given disease area, we map the BMT indications to the Center for Medicare \& Medicated Services' ICD-10 medical classification assessment and group them at the first subchapter level to form a therapeutic category. Examples of categories are "malignant neoplasms of breast" and "disorders of gallbladder, biliary tract and pancreas." 16

\subsection{Paragraph IV Entry Data}

In our analysis, we use the Para-IV generic entry applications associated with each incumbent firm. We obtain the set of Para-IV certifications from the FDA's website. Each observation includes detailed information on the generic-seeking certification, such as product name, dosage form, strength, the reference branded drug, and the first filing date of the generic drug application. On a prospective basis, this information dates back to

16 This provides us with a total of 161 categories from the ICD-10 assessment. 
March of 2004. We supplement this with data from paragraphfour.com, which is a database that compiles detailed information on Paragraph IV cases. For each branded drug, we eliminate repetitions due to dosage form and strength by keeping the earliest generic filing at the drug level. We reason that the profit that is lost by the brand-name owner begins at the first generic entry, and the marginal impact of subsequent generic entry becomes smaller over time. ${ }^{17}$ Using the trade names of branded drugs, we manually match each listed product to a pharmaceutical company in BMT. In total, 431 branded drugs with non-missing filing dates are matched in our sample.

\subsection{Financial Information}

In order to explore the investments and financial decisions of the firms in our sample, we manually match the firms in the BMT database to Compustat. We restrict our analysis to a sample period from 2005 to 2016, due to the availability of Para-IV Entry information. This provides us with a dataset at the firm-year level of 572 public firms with over 3,618 firm-year observations. We collect information on R\&D expenditures, cash holdings, debt levels and earnings, as well as total assets. The first three variables, after being scaled by total assets, are used as outcome variables to quantify the impact of generic threats on a company's financial performance. Additionally, in most regressions, we include lags of these variables as controls.

\footnotetext{
${ }^{17}$ In particular, the first ANDA filer's settlement is key to the process and often dictates what happens to any later Para-IV filers. Furthermore, later settlements are often not relevant. We thank Greg Glass for pointing this out.
} 
Finally, as an alternate measure to better understand the nature of the firm's innovation decisions, we also examine the economic value of new patents issued by each firm, using data from Kogan et al. (2017). ${ }^{18}$

\subsection{Marketing Exclusivity Data}

We use information on the expiration date of exclusivity for each brand drug in order to measure the treatment intensity of incumbents to the FTC $v$. Actavis ruling. We obtain this data from the FDA Orange Book, taken from the National Bureau of Economic Research's (NBER) data repository. Like the data for Para-IV entries, there may be multiple product numbers under each drug's trade name, depending on dosage and strength. We collapse this information at the level of the trade name if there is more than one product expiring in the same year, and we then match drug owners in BMT by the trade name. In total, we match 991 drugs with unique trade names expiring from 2003 to 2022.

\section{Generic Entry and Innovation Outcomes}

We begin this section by providing results that examine the reactions of pharmaceutical firms to Para-IV generic entry.

\subsection{Empirical Methodology}

In our first specification, we run panel regressions to explore the reaction of incumbent firms to entries from generic firms. In order to do so, we construct a variable at the firmyear level that measures how affected a firm is by potential generic threats. More

\footnotetext{
18 Specifically, Kogan et al. (2017) measure excess stock returns around patent issuance dates to create measures of the value that the market places on the new patents.
} 
specifically, we define a variable-Para $I V_{i, t}$ - as the number of firm $i$ 's brand-name drugs for which there is generic entry through a Para-IV certification in year $t$. With this measure, we estimate the following panel regression from 2005 to 2016:

$$
Y_{i, t}=a+\beta_{1} \text { Para IV } V_{i, t-1}+\beta_{2} \text { Para IV } V_{i, t-2}+\gamma \text { Controls }_{i, t}+\mu_{i}+\lambda_{t}+\varepsilon_{i, t}
$$

In equation (3), we include two lags of Para $I V_{i, t}$ in order to account for variations in the timing of responses following Para-IV certifications, and the awareness that the litigation process that begins after an ANDA may take more than one year.

$Y_{i, t}$ is the outcome variable of choice for firm $i$ in year $t$. We focus on two variables as measures of innovation. Initiation $n_{i, t}$ is the number of trials initiated by company $i$ for earlystage projects (that is, pre-clinical or phase 1 ) at time $t$. This measures a company's active exploration of new projects. Suspension ${ }_{i, t}$ is the number of projects in any phase suspended by company $i$ at time $t$. This measures the abandonment (or halting) of ongoing projects by the company.

Controls $s_{i, t}$ is a vector of control variables. We include two variables that we refer to as "pipeline" controls, that characterize the condition of a firm's research pipeline. Avg Approval Probi,t is the average probability of eventual FDA approval for all of company i's projects, which is a proxy for the viability of the firm's development portfolio. Indication Number $_{i, t}$ is the total number of projects in the firm's development portfolio, which acts as a proxy for portfolio size. We also include the natural logarithm of total assets $\log (\mathrm{TA})$ to proxy for firm size and other financial variables, profitability EBIT/TA (measured through earnings before interest and taxes), cash holdings Cash/TA, R\&D expenditures $R \mathcal{} D / T A$, and leverage ratio Debt/TA. ${ }^{19}$ All control variables are lagged by one year except $\log (T A)$.

${ }^{19}$ All of these variables except for $\log (T A)$ are scaled by total assets in order to normalize for size. 


\subsection{Summary Statistics}

Panel A of Table 2 provides summary statistics for the main variables. A typical pharma firm in our sample initiates 2.1 new drug projects in a given year and suspends or terminates 1.3 existing projects every year. This relatively large number of terminations is consistent with the low average approval probability for each project, which is $22.4 \%$ over our sample, implying that more than three-quarters of the projects in development will eventually fail. The average firm in our sample has more than 12 projects in its development pipeline, and its average annual $R \& D$ expenditures are about $64 \%$ of its total assets. This is consistent with the need for a diversified development portfolio and high R\&D expenditures due to the high attrition rate for drug projects.

[Table 2 Here]

Panel B of Table 2 provides the distribution of Para-IV generic filings. In a given year, the majority of firms do not receive generic challenges. This is because a firm will usually only have a small number of approved products losing exclusivity, and furthermore generic manufacturers will selectively target the most profitable ones. Conditional on generic entry occurring, the majority of firms have one product facing Para-IV entry in a given year. GlaxoSmithKline plc had 9 marketed products facing Para-IV entry in 2008, which is the maximum value in our sample.

\subsection{Results}

We begin by exploring how firms respond to generic competition over our sample period. Table 3 provides the estimation results for equation (1). Columns (1) and (2) show that over our full sample, the firm significantly decreases its initiations of new projects in 
response to an increase in Para-IV generic filings that directly affect an incumbent pharmaceutical firm's products. This effect holds for both one-year and two-year lagged Para-IV filings. In columns (3) and (4), we consistently find that firms facing generic entry also increase their suspensions of existing projects. These results suggest that incumbent pharmaceutical firms respond to increased competitive pressures stemming from ParaIV entry by reducing their innovative activities. This is consistent with the first hypothesis in Section 2, as well as the prior empirical evidence in Branstetter, Chatterjee, and Higgins (2014) and Thakor and Lo (forthcoming), in which pharmaceutical firms seem to respond to increased competition by reducing their levels of innovation. ${ }^{20}$

[Table 3 Here]

We now examine whether this effect changes after the FTC $v$. Actavis ruling, in order to determine whether this relationship between competition and innovation is affected by increased antitrust enforcement which diminished the ability of these firms to engage in pay-for-delay agreements. In Table 4, we re-estimate equation (1) but interact our Para IV variables with Post $t$, a dummy variable which takes a value of one if the year is 2013 or later-after the FTC v. Actavis ruling - and zero otherwise.

We find that our previous result reverses itself during the period after the ruling, consistent with our second hypothesis in Section 2. In particular, in the post-ruling period, we find a relative increase in trial initiations and a decrease in trial suspensions when firms face an increase in Para-IV entry. The magnitudes are statistically and economically significant. For example, column (2) shows that before the court ruling, a

${ }^{20}$ One reason for this decrease in innovation may be that there was ex ante uncertainty about competition before realized entries, so the incumbent firm hedges the uncertainty with innovation efforts. But once that uncertainty is resolved with a pay-for-delay agreement, the firm can drop its hedge and reduce its innovative activities. This effect may be exacerbated if an incumbent firm has specialized knowledge capital in a given area from having brought a successful product to the market, which cannot be easily deployed to other areas (e.g. Krieger, Li, and Thakor (2018)). 
firm facing a generic entrant reduced its number of new project initiations by 1.13 , on average, in the following year. In contrast, a firm facing a generic entrant after 2013 responded by initiating an additional 2.24 drugs, which is almost $200 \%$ of the prior reduction, and is larger than the unconditional sample mean number of project initiations for a firm in a given year. Similarly, a firm facing generic competition after 2013 suspends an average of 1.1 to 1.2 fewer projects over the following two years. This magnitude is also comparable to the unconditional mean number of suspensions over the sample. This suggests that, following increased antitrust risk, firms respond to increased competition by increasing their net innovation activity. This is in line with firms feeling the need to "escape the competition" with increased levels of innovation (e.g. Aghion et al. (2005)), given a diminished legal ability to protect their monopoly power. It further suggests that the ability of incumbent firms to enter contracts with newly entering rivals to stave off competition may be a key factor in driving the previously demonstrated negative relationship between competition and innovation. ${ }^{21}$

\section{Diff-in-Diff around FTC v. Actavis}

While the previous results are suggestive of the effect of the increase in antitrust enforcement following the FTC $v$. Actavis ruling, they are subject to concerns about

\footnotetext{
${ }^{21}$ Another potential reason for this result is that an affected firm is experiencing cash or financial constraints after dealing with litigation. If this was the case, we would expect that firms with low cash reserves will reduce their innovation activities more facing generic entry threats. In Table A.2 of the Appendix, we define a variables $L$ Cash $_{i, t}$ that takes a value of 1 if firm $i$ 's cash scaled by total assets is below the median level for all firms in year $t$, and 0 otherwise. We then interact lagged values of this variable with our Para $I V$ variable. We find that the interaction terms are in general insignificant and small in magnitude, indicating a secondorder effect of financial constraints.
} 
potential endogeneity and reverse causality. ${ }^{22}$ In order to overcome these concerns, we run a diff-in-diff analysis, exploiting firm exposure to the ruling.

\subsection{Empirical Methodology}

The FTC $v$. Actavis ruling reduced the ability of firms to engage in pay-for-delay agreements to protect the profits of drugs whose period of FDA marketing exclusivity has expired. As a result, those firms whose drugs are set to expire in the period immediately after the ruling will be the most affected.

Consequently, we define a treatment variable, ExcluLoss2013-2016, which takes a value of one if firm $i$ has a drug with an exclusivity period expiring between 2013 and 2016, and zero otherwise. In our sample, 176 drugs had their marketing exclusivity expire during this period, which provides us with 60 firms in the treatment group. Among the 60 treated firms in our sample, 42 are realized compliers, i.e., their exclusivity-expiring drugs experienced Para-IV generic entry, which further validates the relevance of our treatment variable around the FTC $v$. Actavis ruling. We then run the following diff-indiff regression:

$$
Y_{i, t}=a+\beta_{1} \text { ExcluLoss2013-2016 }_{i} \times \text { Post }_{\mathrm{t}}+\gamma \text { Controls }_{i, t}+\mu_{i}+\lambda_{t}+\varepsilon_{i, t}
$$

In equation (2), as before, Post $t$, is a dummy variable which takes a value of one if the year is after the FTC $v$. Actavis ruling. The validity of the diff-in-diff framework in this case hinges on the observation that firms did not self-select into the treatment group in anticipation of the ruling. We believe that this observation holds in our setting. First, we

\footnotetext{
${ }^{22}$ For example, firms may be able to endogenously affect the Paragraph IV filings intensity through strategies such as "evergreening" their patents (Hemphill and Sampat (2012)). We discuss this issue in further detail shortly. ${ }^{23}$ Specifically, this generates $P 1_{i, j, t}, P 2_{i, j, t}$, and $P 3_{i, j, t}$ for phase 1,2 , and 3 projects, respectively.
} 
will show that the parallel trends assumption likely holds in our setting. Second, as noted earlier, the final ruling from the U.S. Supreme Court was relatively unexpected, preventing self-selection. Finally, since the drug development process is both lengthy and risky (e.g. Wong, Siah, and Lo (2019)), lasting an average of 8 years before a drug is potentially approved and able to gain exclusivity, this makes it effectively impractical for firms to be able to choose their treatment intensity, as the choice to begin the project had been made several years earlier.

We further expand our analysis to examine effects at the firm-therapeutic category level, which allows us to explore decisions at distinct R\&D units within a firm (Henderson and Cockburn, 1994). In our sample, an average firm operates in 7.28 ICD categories, each of which is defined as a therapeutic area. Exploiting different combinations of fixed effects in equation (2) at the therapeutic area level, we are able to estimate both betweenfirm and within-firm effects, which allows us to examine whether a firm experiencing generic entry in a particular area increases or decreases its innovation relative to other areas within the same firm, as well as relative to other firms operating within the same area. In particular, we define ExcluLoss2013-2016 $6_{i, j}$ as taking a value of one if firm i's therapeutic category $j$ has a drug with exclusivity period expiring between 2013 and 2016, and zero otherwise. Initiations $s_{i, j, t}$ and Suspensions $s_{i, j, t}$ are defined similarly as before, except that the number is counted for firm $i$ 's therapeutic category $j$ at $t$. In this new specification, we do not include financial control variables since we include firm-year fixed effects. However, we add more granular therapeutic category level pipeline control variables. In addition to Avg Approval Prob $i, j, t$, we control for the total number of active projects in each different phase. ${ }^{23}$ We also construct Approvals $s_{i, j, t}$ as the number of total approved drugs

\footnotetext{
${ }^{23}$ Specifically, this generates $P 1_{i, j, t,}, P 2_{i, j, t}$ and $P 3_{i, j, t}$ for phase 1,2 , and 3 projects, respectively.
} 
from 2000 to year $t$ in firm $i$ 's therapeutic category $j$. As before, all control variables are lagged by one year.

\subsection{Results: Project Innovation Outcomes}

The results estimating equation (2) at the firm-year level are given in Table 5 Panel A. We find that firms in the treatment group - those with exclusivity-expiring drugs in the postruling period-increase the number of their new project initiations, and decrease the number of their suspensions relative to the control group following the FTC $v$. Actavis court ruling. In particular, a firm affected by the court ruling initiates 2.47 more new drugs projects and suspends 1.62 fewer projects, on average, relative to the control group. The magnitudes are consistent with the estimates in Table 4 and larger than the unconditional sample means. These results are consistent with our previous results that firms increase their net innovation activities following a reduction in their ability to engage in pay-for-delay agreements with future entrants.

[Table 5 Here]

We then confirm that our results are consistent at a more granular level. In Table 5 Panel B, we replicate the diff-in-diff analysis at the firm-therapeutic area level. In columns (1) and (2), we include firm-ICD fixed effects and year fixed effects. The results indicate that the increase in innovation activities occur both between firms as well as within firms. In columns (3) and (4), we add category-year fixed effects along with firm fixed effects. This allows us to compare within a given therapeutic category in a given year, how an affected firm's activities differ from non-affected ones. In columns (5) and (6), we provide estimation results with therapeutic area fixed effects and firm-year fixed effects. This enables us to compare within a given firm, whether a firm's innovation in an affected therapeutic category differs from its innovation in other therapeutic categories. The 
estimated magnitudes are consistent across different specifications. This suggests that treated firms increase their innovation activities relative to unaffected firms that target the same market and center their actions directly on the affected category. Furthermore, firms increase their innovation activity in affected areas relative to unaffected areas in the same firm.

\subsection{Results: Innovation Value}

The results in the previous section echo those in Section 5, that firms appear to increase their innovation activitives once they have a diminished ability to fend off competition. In order to provide more color behind these results, we now examine an additional measure of innovation: the economic value of new patents issued by firms (Kogan et al. (2017)).

Examining this measure is appealing for a few reasons. First, it allows us to examine a patent-related measure of innovation as an alternative to project starts and stops, in order to reinforce our results. In particular, beyond the disadvantages of using patent counts that were previously mentioned, in our setting patent counts are problematic, because biopharma companies commonly used "evergreening" strategies when they were able to freely use pay-for-delay agreements, in which firms would issue new patents on existing drugs to extend the patent protection length. This would permit incumbents to better negotiate with generic manufacturers (see e.g., Hemphill and Sampat (2012)). These new patents tended to be minor modifications of mixtures of delivery methods of older drugs. ${ }^{24}$ Using patent value instead allows us to account for this possibility. Second,

\footnotetext{
${ }^{24}$ Consistent with this, in untabulated results we find insignificant effects when using patent counts as our outcome variable. An alternative measure would be to use the citation-weighted number of patents, in which each patent is weighted by its own forward citations divided by the average citations of all patents
} 
using patent value allows us to examine a measure of "quality" - as proxied by economic value-of the new innovations that the firm is undertaking. For example, a firm may choose to initiate more drug trials, resulting in a higher volume of innovation, but this may not reflect promising or novel drug candidates or significant innovation.

In Table 6, we repeat our analysis from Table 5, using Patent Valuei,t as the outcome variable. The results show that for affected firms after the FTC $v$. Actavis ruling, the economic value of new patents significantly increased relative to other firms. In particular, the magnitude indicates that the economic value of new patents increased for treated firms by $\$ 284$ to $\$ 349$ million, an increase of around two times the sample unconditional average patent value. This reinforces the previously results on the increase in project starts and decrease in project stops, and also provides evidence that this new innovation is relatively more valuable, in line with increased development efforts by these firms. ${ }^{25}$

[Table 6 Here]

\subsection{Parallel Trends}

A critical assumption of any diff-in-diff setting is the parallel trends assumption, that there are no pre-trends between the treatment and control groups. In order to validate this assumption, we interact our treatment variable ExcluLoss2013-2016 $i$ with individual year indicators instead of Post t. 26 This allows us to examine whether there are any

\footnotetext{
issued in the same year (e.g. Hall et al. (2005) and Kogan et al. (2017)). Patents issued in the treatment period (2013 to 2016) tend to suffer from truncation bias and have fewer citations. For example, the average biotech patent issued in 2016 has 0.7 citations.

${ }^{25}$ We cannot use Patent Value $_{i, t}$ as an outcome variable at the firm-therapeutic category level since we are unable to allocate each patent to unique drug categories within a given firm. A single patent may be associated with the development of multiple drugs from different therapeutic areas.

${ }^{26}$ We include all individual years except 2012, which serves as the reference year. The figures are qualitatively similar across other specifications.
} 
differential effects between the treatment and control firms in the years before the ruling. The coefficients are plotted in Figure 3, along with their 95 percent confidence intervals. For both initiations and suspensions, the coefficients show no discernible pre-trend before the ruling. After the ruling, the coefficient estimates for initiations and patent value increase in magnitude and significance, while the coefficient estimates for suspensions decline and turn significant. This suggests that the parallel trends assumption holds for our setting.

[Figure 3 Here]

\subsection{Robustness}

We conduct a number of robustness checks for our main results. First, a potential concern is that firms losing marketing exclusivity will always respond by innovating more, regardless of the availability of pay-for-delay agreements. However, we argue that before the FTC $v$. Actavis ruling, since firms can strategically use these payments to defend against generic entrants, the loss of marketing exclusivity poses a smaller concern. To show this, we perform a placebo test by counterfactually assuming that the ruling occurred in 2009, and use the firms losing exclusivity from 2009 to 2012 as the pseudotreatment group. ${ }^{27}$ In Table A.1 of the Appendix, we find insignificant results for all of our main outcome variables.

Second, we also examine the innovation incentives around the FTC v. Actavis ruling in a different way through an instrumental variables (IV) analysis. More specifically, we instrument for the Para-IV filings that each firm faces-both over the entire sample and

\footnotetext{
${ }^{27}$ The cutoff is chosen so that the pseudo-treatment group does not overlap with the actual treatment group. In this analysis, we drop all firm-year observations after 2013 to perform a clean test, although our placebo test results are robust to including the later sample.
} 
for the post-ruling period - using the number of exclusivity-expiring drugs for each firm. This uses the idea that generic firms will naturally enter the market once a brand-name firm's exclusivity expires. Using instrumented Para-IV filings, we then examine innovation outcomes. The results are given in the Appendix in Tables A3 and A4 (accounting for one- and two-year lags), and confirm the previous results.

\subsection{Heterogeneity}

To further reinforce the proposed channels driving our results, we examine heterogeneity in our main effect in terms of firms that are ex ante predicted to respond more strongly to the ruling. Grabowski and Kyle (2007) show that profitable brand-name drugs attract more generic competition. As a result, incumbent firms whose exclusivity-expiring drugs have relatively high sales (i.e. "blockbuster" drugs) should be more affected by the ruling. Furthermore, firms with a relatively large number of exclusivity-expiring drugs should also be more affected by the ruling.

In order to explore this predicted effect, we split our treatment group based on these two criteria. To identify high-sales drugs, we collect the top 100 brand-name drugs by sales in 2012 and 2013 from the website drugs.com and match them to their commercializing firms. We then construct two variables: HSale $e_{i}$ takes a value of one if firm $i$ has an exclusivity-expiring drug that is in the top 100 sales list (a blockbuster drug) and zero otherwise, and LSale $i$ takes a value of one if firm $i$ has an exclusivity-expiring drug that is not in the top 100 sales list and zero otherwise. There are a total of 19 treated firms for which $\mathrm{HSale}_{i}=1$, accounting for roughly one-third of the total; the rest of treated companies are $L S a l e_{i}=1$. To identify firms with relatively large numbers of exclusivityexpiring drugs, we construct two additional variables. HNumi takes a value of one if firm $i$ has above the median number of exclusivity-expiring drugs in 2013 to 2016 and zero 
otherwise, and $\mathrm{LNum}_{i}$ takes a value of one if firm $i$ has below the median number of exclusivity-expiring drugs in 2013 to 2016 and zero otherwise. ${ }^{28}$

The results are given in Table 7. As the table shows, the effects concentrate on the firms likely to be the most exposed to the FTC $v$. Actavis ruling: firms with relatively higher sales, and the firms with the highest number of drugs with exclusivity expiring in the 2013 to 2016 period. The difference is substantial. For example, the high-sales affected group significantly increased their new project initiations by 5.48 drugs and decreased their suspensions of existing projects by 3.58 drugs, which are both around 2.2 times larger than the average treatment effects. On the other hand, the low-sales affected group's reactions are close in magnitude to 0 and are insignificant. The results for the high-number and low-number groups follow the same pattern.

[Table 7 Here]

\subsection{Additional Outcomes}

We provide a number of additional analyses in this section to provide more firm-specific detail to our results.

First, we examine project acquisitions as an outcome variable. Innovative firms have a choice between "internal" and "external" innovation-i.e. conducting R\&D in-house, or acquiring it from another firm. Thus, our previous results may understate or overstate the project decision incentives of a firm, since acquisitions are an alternative to the initiation of a new project within the firm. In order to explore this, we re-estimate equation (2) using two measures of project acquisitions. DrugAcq $q_{i, t}$ is defined as the number of drugs acquired from other companies, while EarlyDrugAcq ${ }_{i, t}$ is the number of

${ }^{28}$ The median number of exclusivity-expiring drugs is two. 
acquired drugs in preclinical or phase 1 from other companies (a closer substitute to initiating a new drug project). We note that these are not whole-firm acquisitions, but rather acquisitions of the intellectual property rights of a drug project. Furthermore, we ensure that the acquired project is a new brand-name drug in development, rather than a competing generic drug. ${ }^{29}$

The first two columns of Table 8 provide the estimated results. Firms subsequent to the ruling increase their acquisitions of projects from other firms, for all project phases, and for early-stage projects. For example, in column (1), a treated firm acquires an average of 0.274 additional drug projects compared to a control firm following the ruling, which is slightly lower than the unconditional average of the treatment group (0.36). ${ }^{30}$ Only one-third (0.086) of such acquisitions are for early-stage drugs, defined as drugs in preclinical or phase 1, as indicated in column (2). This suggests that firms use acquisitions as another mechanism to increase their net innovative activity in response to a diminished ability to protect their monopoly power. The smaller magnitude for earlystage acquisitions indicates that these firms are pursuing late-stage projects as a quicker response to negative shocks (e.g. Krieger et al. 2018, Bena and Li (2014)).

[Table 8 Here]

We next examine the broader firm-level outcomes around the FTC v. Actavis ruling. In particular, we examine R\&D expenditure to see the overall firm investment, and also cash holdings and capital structure to see the ways that firms are funding their increase in innovation outcomes. In line with the increase in project initiations and acquisitions,

29 Therefore, our results are not driven by the incentives of killer acquisitions (Cunningham et al. 2021).

${ }^{30}$ We report the unconditional mean of the treatment group because it tends toward large pharmaceutical firms, which are the common acquirers in this industry. The existence of many smaller (and financially constrained) biotech firms over the whole sample will underestimate the overall sample propensity of acquisition. 
we see a relative increase in $R \& D$ expenditure of $25 \%$ of total assets for affected firms, consistent with firms planning new projects, which is roughly $40 \%$ of the unconditional average value of $R \mathcal{E} D / T A_{i, t}$. Hand-in-hand with this increase in $R \& D$ expenses, cash holdings significantly decrease and leverage goes up. This suggests that firms are drawing down their cash holdings and increasing their debt in order to fund new R\&D, which is in line with in-house innovations and external acquisitions being financed by a combination of internal cash and external (debt) financing.

\subsection{Litigation Outcomes}

Taken as a whole, our results are consistent with the hypothesized effect of pay-for-delay settlements on innovation outcomes. However, a shortcoming of our analysis is that we do not directly measure the precise details of pay-for-delay settlements at the firm level, such as settlement terms and litigation costs, since these details are confidential. ${ }^{31}$

To address this issue, and to provide more evidence of the effects of the FTC v. Actavis ruling on pay-for-delay settlements, we hand-collect a variety of additional variables from the "Legal Proceedings" sections of 10-K filings, extracting any mentions of generic litigation cases. We identify cases at the brand-name drug and generic entrant level. Since companies do not fully disclose all cases, we also supplement our data with handcollected information from news articles via Law360 and LexisNexis.

With this data, we construct three additional measures. First, we define Settlement $t_{i, t}$ as the number of firm $i$ 's projects for which there are Para-IV settlements in year $t$. This is a fuzzy measure that counts both regular loyalty settlements as well as pay-for-delay

\footnotetext{
${ }^{31}$ In other words, even though we can observe whether there exists a settlement for generic entry, the terms of the settlement are confidential and thus unobservable, and we therefore cannot categorize it by whether pay-for-delay activities are involved.
} 
agreements. Second, we define CourtNumi,t as the number of Para-IV court cases for firm $i$ in year $t$ which conclude with a court ruling. Finally, EntryRuling $g_{i, t}$ is the number of court cases for firm $i$ in year $t$ which conclude with a ruling in which the generic drug is allowed to enter into the market.

Given our hypothesis about the effect of the FTC $v$. Actavis ruling, the number of settlements should go down for affected incumbent firms, since engaging in pay-fordelay agreements carries a higher legal risk. Similarly, in the absence of pay-for-delay settlements, the number of cases with court rulings and cases in which the generic drug allowed to enter the market are predicted to go up for affected firms after the ruling.

Table 9 provides the estimation results for the litigation outcomes with the diff-in-diff analysis. In terms of Para-IV settlements, column (1) shows that the propensity of an incumbent firm reaching a deal with a generic entrant goes down, although it is not statistically significant. Columns (2) and (3) explore the number of court cases with rulings and the number of court rulings that allow generic entry. Both outcomes are significantly positive, confirming that the affected firms become more likely to wait for court rulings (rather than settling), which tend to lead to direct entry by competitors, as previously noted.

[Table 9 Here]

\section{Therapeutic Area Analysis}

In the final part of our analysis, we explore the aggregate implications of these effects by examining the overall innovation activity in specific therapeutic categories. The aggregate effects are not clear-cut a priori. On the one hand, we have shown that incumbents increase their innovation in response to generic entry when hindered in their 
ability to use pay-for-delay agreements. On the other hand, increased innovative activity on the part of incumbents may serve as a deterrent to potential (non-generic) entrants, as it may be more difficult to compete against the incumbent's increased efforts. Furthermore, a diminished ability to protect monopoly power may weaken the ex ante incentives of firms that innovate in order to gain that monopoly power. ${ }^{32}$

We explore this issue by examining a variety of outcomes over our sample period at the aggregated therapeutic category level, which we index by $j$. More specifically, we examine the total number of project suspensions, Suspensions $j_{j, t}$, and acquisitions of new projects, $\operatorname{DrugAcq} q_{j, t}$. Since we are particularly interested in the development of new drugs, we also count the total number of new drug project initiations, Initiations $s_{j, t}$, and further sub-divide this count into drug project initiations by incumbent firms, IncInitiation ${ }_{j, t}$, and drug project initiations by new entrants, EntInitiation ${ }_{j, t}$. Finally, Entrants $s_{j, t}$ is the number of firms entering into the therapeutic category with new drug projects. It should be emphasized that the entrants defined here are not the generic manufacturers aiming to producetheir current drugs with Para-IV filings, but rather are firms that are developing their own brand-name drugs. We include fixed effects by therapeutic category and year, as well as several controls, including the lagged number of projects under development in the category, the number of incumbent firms operating in the category, and the average likelihood of approval for all current projects in the category.

With these outcome variables, we run a diff-in-diff specification. Our treatment variable is ExcluLoss2013-2016; , a binary variable that takes a value of one if area $j$ has at least one approved product lose its market exclusivity between 2013 and 2016, and zero otherwise. We multiply this variable with the Post $t_{t}$ variable to construct the diff-in-diff

\footnotetext{
32 Indeed, motivating entrants was the rationale behind the FDA introducing a marketing exclusivity period for newly approved drugs.
} 
estimator in this setting. Our results are robust to using alternative measures such as the realized number of Para-IV filings or the number of drugs losing their exclusivity in the post-treatment period.

The results are given in Table 10. Consistent with the firm-level analysis, we find that the therapeutic areas affected by the FTC $v$. Actavis ruling have a relatively smaller number of drug suspensions and a greater number of drug acquisitions. Interestingly, column (3) shows that the total number of initiations of new drugs in a given category increases in response to the shock, although the effect is insignificant. Examining this effect more closely, we find that in an affected area, incumbents respond by increasing their initiations significantly (column 4). However, we find negative effects with respect to new entrants in the therapeutic area after examining the extensive margin in columns (4) and (6). In particular, following the ruling, there is a decline in the number of new entrants into the affected area, as well as a decline in the number of drug trials initiated by entering firms. This result also sheds light on the structure of competition following the FTC $v$. Actavis ruling: while competition for existing drugs increases following the ruling, via increased generic competition, competition for new ideas declines, due to fewer entering firms.

\section{[Table 10 Here]}

Put together, the results suggest an interesting consequence of the constraint on payfor-delay agreements. On the one hand, at a more highly aggregated level, restricting pay-for-delay agreements seems to have increased innovation by firms already operating in a given therapeutic area. On the other hand, new (non-generic) entrants appear to have diminished incentives to innovate in a therapeutic area in response to generic filings following the ruling. There are numerous potential reasons for this result. Unlike incumbent companies that are motivated to maintain their market position, entrants may 
be concerned about their loss of profitability from increased generic activity, given the unavailability of pay-for-delay agreements that previously staved off generics from entering the market. Alternatively, it may be that the increased innovation activity by incumbent firms serves as a deterrent to new companies entering the space, given the incumbent's built-up stock of knowledge capital from bringing its earlier drug to market. 33

Our results are broadly consistent with results pointed out in previous empirical and theoretical work about the dynamics of incumbent responses to increased competition. Lichtenberg and Philipson (2002) note that market competition in the pharmaceutical industry can take on the forms of both within-patent and between-patent competition. Generic replacement is an example of within-patent competition, while better novel drugs under new patents are an example of between-patent competition. These different types of competition have differing effects in terms of innovation outcomes. For example, Gilchrist (2016) finds that a one-year increase in the marketing exclusivity period of a newly approved drug increases subsequent entry by 0.2 drugs. Our results add the new insight that antitrust regulation in innovative sectors may result in one type of competition (within) increasing at the expense of the other (between).

Our findings also map to the theoretical work of Segal and Whinston (2007). While antitrust policy in innovative industries usually focuses on the trade-off between R\&D incentives and monopoly pricing, there is also a dynamic tension between incumbents and potential new innovators. New inventors stand on the shoulders of the old ones and may replace them. However, once entrants successfully do so, they themselves become the targets of newcomers. Limiting the ability of incumbents to create market barriers

\footnotetext{
${ }^{33}$ See, for example, Krieger, Li, and Thakor (2018) for an example of how built-up knowledge capital can keep incumbents in a given space, but can cause new entrants to flee a space given a negative shock.
} 
permits new entry but does not guarantee it, because the same restrictions will apply to the new entrants once they succeed and gain market share.

\section{Conclusion}

In this paper, we examine the relationship between competition and innovation through exploring a particular legal mechanism by which firms may endogenously maintain their market power: pay-for-delay agreements. We explore this using detailed data from the pharmaceutical industry, using a Supreme Court ruling that made such agreements legally risky and subject to antitrust enforcement. Before the ruling, we find a negative relationship between competitive entry and innovation by incumbent firms, but this relationship reverses itself following the ruling. This result suggests that firms that are able to protect their monopoly power through pay-for-delay agreements face dampened incentives to innovate, and that restricting such agreements through antitrust law may increase their innovation incentives. However, we also show that the ruling had a negative effect on firm entry into areas with heavy generic competition, suggesting that the effects on competition at the extensive margin may differ.

Overall, our results provide evidence for a complex effect of competition on innovation. This has implications for the use of antitrust law to promote innovation. In particular, the results suggest that a nuanced approach must be taken to regulation aimed at influencing competition. If the regulatory goal is to stimulate innovation, then it is not enough to enact laws and regulations that increase competition. Rather, the encouragement of increased competition has to be accompanied by initiatives that limit the contracting options for incumbents to nullify the regulatory attempt to elevate competition. Only when this is done does greater competition stimulate innovation. 


\section{References}

Acemoglu, Daron, and Ufuk Akcigit. "Intellectual property rights policy, competition and innovation." Journal of the European Economic Association 10, no. 1 (2012): 1-42.

Aghion, Philippe, Christopher Harris, Peter Howitt, and John Vickers. "Competition, imitation and growth with step-by-step innovation." The Review of Economic Studies 68, no. 3 (2001): 467-492.

Aghion, Philippe, Nick Bloom, Richard Blundell, Rachel Griffith, and Peter Howitt. "Competition and innovation: An inverted-U relationship." The Quarterly Journal of Economics 120, no. 2 (2005): 701-728.

Ahn, Sanghoon. "Competition, innovation and productivity growth: a review of theory and evidence." (2002).

Bena, Jan, and Kai Li. "Corporate innovations and mergers and acquisitions." The Journal of Finance 69, no. 5 (2014): 1923-1960.

Berndt, Ernst R., and Murray L. Aitken. "Brand loyalty, generic entry and price competition in pharmaceuticals in the quarter century after the 1984 WaxmanHatch legislation." International Journal of the Economics of Business 18, no. 2 (2011): 177-201.

Branstetter, Lee, Chirantan Chatterjee, and Matthew J. Higgins. Starving (or fattening) the golden goose?: Generic entry and the incentives for early-stage pharmaceutical innovation. No. w20532. National Bureau of Economic Research, 2014.

Branstetter, Lee, Chirantan Chatterjee, and Matthew J. Higgins. "Regulation and welfare: evidence from paragraph IV generic entry in the pharmaceutical industry." The RAND Journal of Economics 47, no. 4 (2016): 857-890.

Bulow, Jeremy. "The gaming of pharmaceutical patents." Innovation policy and the economy 4 (2004): 145-187.

Corhay, Alexandre, Howard Kung, and Lukas Schmid. "Q: risk, rents, or growth?" Working Paper, 2021.

Corhay, Alexandre, Howard Kung, and Lukas Schmid. "Competition, markups, and predictable returns." The Review of Financial Studies 33, no. 12 (2020): 5906-5939. 
Cunningham, Colleen, Florian Ederer, and Song Ma. "Killer acquisitions." Journal of Political Economy 129, no. 3 (2021): 000-000.

DiMasi, Joseph A., and Grabowski, Henry G. "The cost of biopharmaceutical R\&D: is biotech different?" Managerial and Decision Economics 28, no. 4-5 (2007): 469-479.

Freilich, Janet. "Prophetic Patents." (2018).

FTC Study, 2002. Generic Drug Entry Prior to Patent Expiration: An FTC Study. Washington (DC): Federal Trade Commission.

Gans, Joshua S., David H. Hsu, and Scott Stern. "When Does Start-up Innovation Spur the Gale of Creative Destruction?" RAND Journal of Economics 33, no. 4 (2002): 571586.

Gans, Joshua S., and Scott Stern. "The Product Market and the Market for Ideas": Commercialization Strategies for Technology Entrepreneurs." Research Policy 32, no. 2 (2003): 333-350.

Gans, Joshua S., and Scott Stern. "Managing Ideas: Commercialization Strategies for Biotechnology." (2003).

Garfinkel, Jon, and Mosab Hammoudeh. "Competition Threats and Rival Innovation Responses: Evidence from Breakthrough Therapies". Working paper (2020).

Gilbert, Richard, and Carl Shapiro. "Optimal patent length and breadth." The RAND Journal of Economics (1990): 106-112.

Gilchrist, Duncan S. "Patents as a spur to subsequent innovation? evidence from pharmaceuticals." American Economic Journal: Applied Economics 8, no. 4 (2016): 189221.

Grabowski, Henry. "Are the economics of pharmaceutical research and development changing?." Pharmacoeconomics 22, no. 2 (2004): 15-24.

Grabowski, Henry. "Competition between generic and branded drugs." Pharmaceutical innovation: incentives, competition, and cost-benefit analysis in international perspective (2007): 153-73. 
Grabowski, Henry G., and Margaret Kyle. "Generic competition and market exclusivity periods in pharmaceuticals." Managerial and Decision Economics 28, no. 4-5 (2007): 491-502.

Grabowski, Henry G., and John M. Vernon. "Brand loyalty, entry, and price competition in pharmaceuticals after the 1984 Drug Act." The Journal of Law and Economics 35, no. 2 (1992): 331-350.

Hall, Bronwyn H., Adam Jaffe, and Manuel Trajtenberg. "Market value and patent citations." RAND Journal of economics (2005): 16-38.

Helland, Eric, and Seth A. Seabury. Are settlements in patent litigation collusive? Evidence from Paragraph IV challenges. No. w22194. National Bureau of Economic Research, 2016.

Henderson, Rebecca, and Iain Cockburn. "Measuring competence? Exploring firm effects in pharmaceutical research." Strategic Management Journal 15, no. S1 (1994): 63-84.

Higgins, Matthew J., and Stuart JH Graham. "Balancing innovation and access: patent challenges tip the scales." Science 326, no. 5951 (2009): 370-371.

Hopenhayn, Hugo, Gerard Llobet, and Matthew Mitchell. "Rewarding sequential innovators: Prizes, patents, and buyouts." Journal of Political Economy 114, no. 6 (2006): 1041-1068.

Kelly, Patrick. "Prophetic Patents in Biotechnology." Nature Biotechnology 8, no. 1 (1990): 24.

Klemperer, Paul. "How broad should the scope of patent protection be?." The RAND Journal of Economics (1990): 113-130.

Krieger, Joshua, Xuelin Li, and Richard T. Thakor. "Find and replace: R\&D investment following the erosion of existing products." Available at SSRN 3240344 (2018).

Leonid Kogan, Dimitris Papanikolaou, Amit Seru, Noah Stoffman, "Technological Innovation, Resource Allocation, and Growth", The Quarterly Journal of Economics, Volume 132, Issue 2, May 2017 
Lichtenberg, Frank R., and Tomas J. Philipson. "The dual effects of intellectual property regulations: within-and between-patent competition in the US pharmaceuticals industry." The Journal of Law and Economics 45, no. S2 (2002): 643-672.

Reiffen, David, and Michael R. Ward. "Generic drug industry dynamics." Review of Economics and Statistics 87, no. 1 (2005): 37-49.

Segal, Ilya, and Michael D. Whinston. "Antitrust in innovative industries." American Economic Review 97, no. 5 (2007): 1703-1730.

Thakor, Richard T., and Andrew W. Lo. "Competition and R\&D financing: Evidence from the biopharmaceutical industry." Journal of Financial and Quantitative Analysis, forthcoming.

Tirole, Jean. The theory of industrial organization. MIT press, 1988.

Williams, Heidi L. "Intellectual property rights and innovation: Evidence from the human genome." Journal of Political Economy 121, no. 1 (2013): 1-27.

Wong, Chi Heem, Kien Wei Siah, and Andrew W. Lo. "Estimation of clinical trial success rates and related parameters." Biostatistics 20, no. 2 (2019): 273-286. 


\section{Figure 1: Timeline of Generic Entry for a Given Drug}

This figure plots the timeline of generic entry for each brand-name drug.

Patent
Granted




\section{Figure 2: Pay-for-Delay Settlements over Time}

This figure plots the trend of pay-for-delay settlements around the decision of FTC $v$. Actavis (dashed line). Data are from the FTC's annual report on Medicare Modernization Act Agreement Filings.

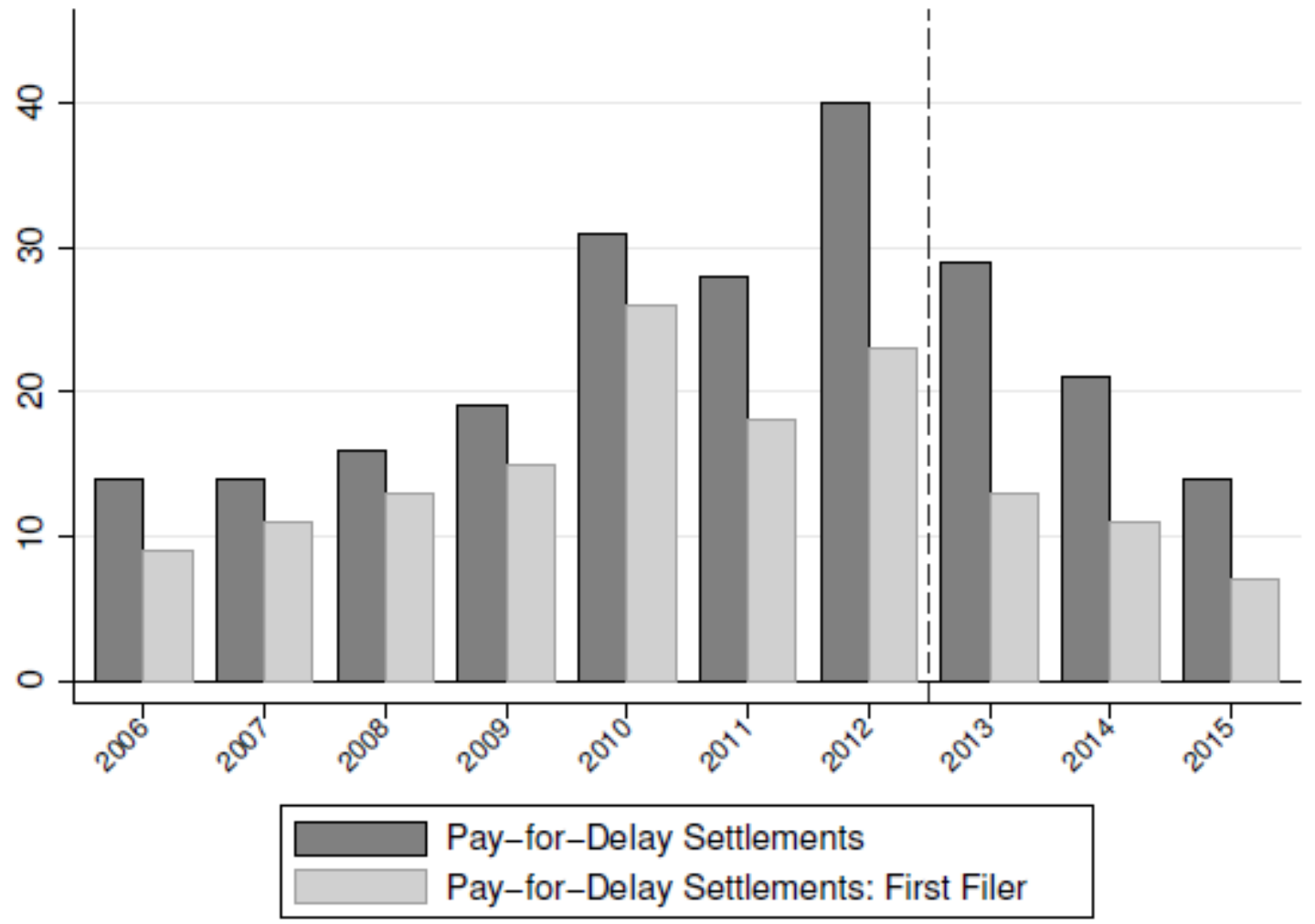




\section{Figure 3: Diff-in-Diff Coefficient Dynamics}

This figure provides coefficient dynamics for the main specification, with individual year indicators replacing the Post $_{t}$ variable. 95\% confidence interval bands are shown along with the point estimates.

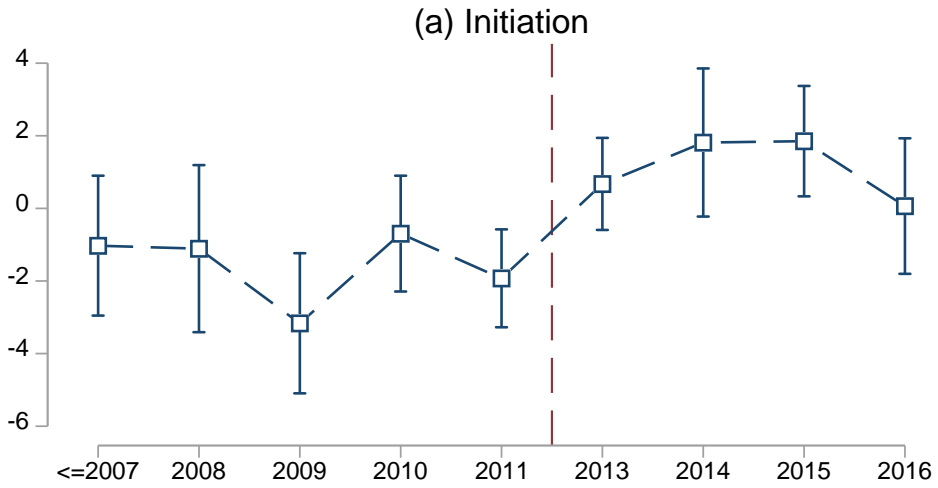

(b) Suspension

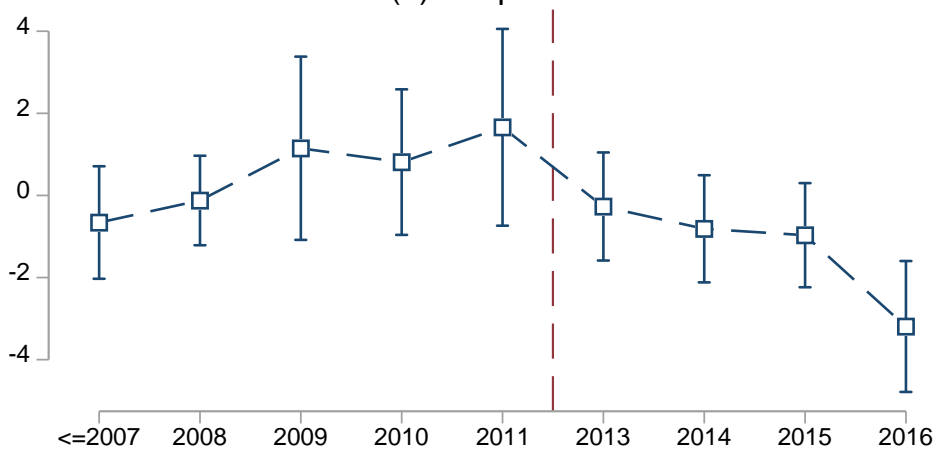

(c) Patent Value

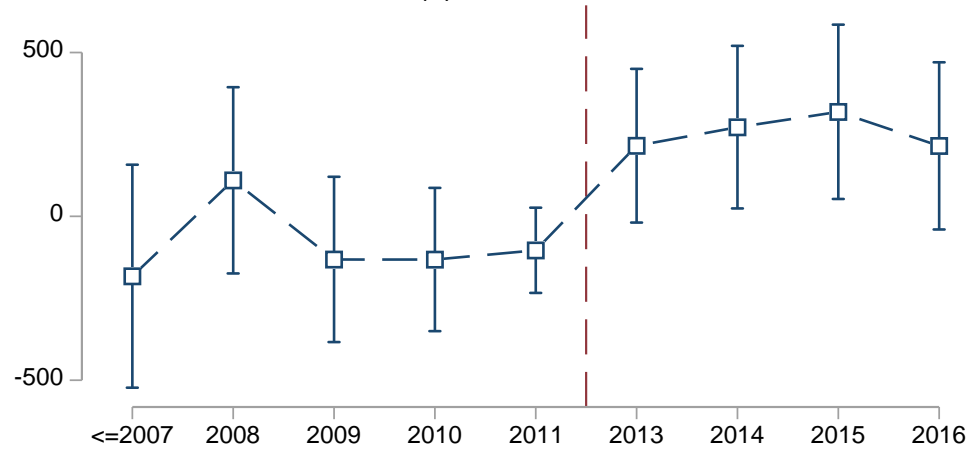




\section{Table 1: Pay-for-Delay Settlements over Time}

This table summarizes the number of brand-name drugs involved with first-time Para-IV ANDA filings and litigation settlement information related to first generic filers. The settlement information is from the FTC's annual report on Medicare Modernization Act Agreement Filings. Brand-name drugs' Para-IV filing information is from the FDA's website. For each branded drug, we aggregate over the dosage form and strength, and we only keep the first Para-IV submission per year. Each brand-name drug may have multiple bilateral settlements with different generic entrants.

Year

20052006200720082009201020112012201320142015

\begin{tabular}{|c|c|c|c|c|c|c|c|c|c|c|c|}
\hline $\begin{array}{c}\text { Brand-name Drugs with First } \\
\text { Para-IV Filers }\end{array}$ & 38 & 34 & 44 & 58 & 59 & 45 & 40 & 40 & 44 & 40 & 40 \\
\hline $\begin{array}{c}\text { Final Settlements Involving } \\
\text { First Filers }\end{array}$ & 5 & 11 & 16 & 29 & 32 & 49 & 54 & 43 & 41 & 53 & 39 \\
\hline Pay-for-Delay Settlements & 3 & 14 & 14 & 16 & 19 & 31 & 28 & 40 & 29 & 21 & 14 \\
\hline $\begin{array}{l}\text { Pay-for-Delay Settlements } \\
\text { Involving First Filers }\end{array}$ & 2 & 9 & 11 & 13 & 15 & 26 & 18 & 23 & 13 & 11 & 7 \\
\hline
\end{tabular}




\section{Table 2: Summary Statistics}

This table provides the summary statistics for major variables. In Panel A, Initiations is the number of new drug trial initiations. Suspensions is the number of suspensions of drug trials. PatentValue is the total economic value (\$ millions) of patents issued by a given firm. Avg Approval Prob is the average likelihood of approval of a firm's drug portfolio. Indication Number is the number of projects in a firm's drug portfolio. The financial variables are the natural log of total assets $\log (T A)$, cash holdings Cash/TA, R\&D expenditures $R \mathcal{E} D / T A$, and leverage ratio Debt/TA. The statistics include the number of non-missing observations $(N)$, Mean, standard deviation (Std), $25^{\text {th }}$ percentile $(p 25)$, median ( $\left.p 50\right)$, and 75 th percentile ( $\left.p 75\right)$. In Panel B, the value distribution of Para $I V_{i, t}$ is provided. Para $I V_{i, t}$ is the number of firm $i$ 's drugs affected by Paragraph IV entrants.

Panel A: Summary Statistics

\begin{tabular}{|c|c|c|c|c|c|c|}
\hline Variables & $N$ & Mean & Std & $p 25$ & p50 & P75 \\
\hline Initiations $s_{i, t}$ & 3618 & 2.093 & 5.135 & 0.000 & 0.000 & 2.000 \\
\hline Suspensions $i_{i, t}$ & 3618 & 1.313 & 4.665 & 0.000 & 0.000 & 1.000 \\
\hline Avg Approval Prob $i, t$ & 3618 & 22.372 & 15.376 & 11.467 & 20.000 & 29.364 \\
\hline Indication Number ${ }_{i, t}$ & 3618 & 12.033 & 31.194 & 2.000 & 4.000 & 8.000 \\
\hline $\log (T A)_{i, t}$ & 3613 & 4.274 & 2.360 & 2.761 & 4.070 & 5.265 \\
\hline $\mathrm{Cash} / \mathrm{T} A_{i, t}$ & 3613 & 0.640 & 0.301 & 0.408 & 0.737 & 0.907 \\
\hline$R \mathcal{E D} / \mathrm{T} A_{i, t}$ & 3606 & 0.636 & 1.227 & 0.151 & 0.322 & 0.599 \\
\hline $\operatorname{Debt} / \mathrm{T} A_{i, t}$ & 3584 & 0.391 & 1.005 & 0.000 & 0.033 & 0.299 \\
\hline PatentValue $_{i, t}$ & 3618 & 166.712 & 781.347 & 0.000 & 0.000 & 9.890 \\
\hline
\end{tabular}

Panel B: Para IV Value Distribution

\begin{tabular}{lcccccc}
\hline Para IV $V_{i, t}$ Value & 0 & 1 & 2 & 3 & 4 & $>4$ \\
\hline Count & 3,391 & 125 & 52 & 26 & 10 & 14 \\
Percentage & $93.73 \%$ & $3.45 \%$ & $1.44 \%$ & $0.72 \%$ & $0.28 \%$ & $0.39 \%$ \\
\hline
\end{tabular}




\section{Table 3: Generic Entry and Innovation Activity}

This table provides estimate results for innovation outcomes for equation (1). Para $I V_{i, t}$ is the number of firm $i$ 's drugs affected by Paragraph IV entrants. Initiations $s_{i, t}$ is the number of new drug trial initiations. Suspensions ${ }_{i, t}$ is the number of suspensions of drug trials. Avg Approval Prob is the average likelihood of approval of a firm's drug portfolio. Indication Number is the number of projects in a firm's drug portfolio. In columns (2) and (4), we include the log of total assets $\log (T A)$, and the lagged value of profitability EBIT/TA (measured through earnings before interest and taxes), cash holdings Cash/TA, R\&D expenditures $R E D / T A$, and leverage ratio Debt/TA. Regressions are run from 2005 to 2016. T-statistics are reported in parentheses, and robust standard errors are clustered at the firm level. A constant term (not reported) is included in all regressions. Firm and year fixed effects are included in all specifications, as indicated. ${ }^{* *},{ }^{* *}$, and * indicate significance at the $1 \%, 5 \%$, and $10 \%$ levels, respectively.

\begin{tabular}{|c|c|c|c|c|}
\hline Dependent Variable: & $\begin{array}{c}(1) \\
\text { Initiations }{ }_{i, t}\end{array}$ & $\begin{array}{c}(2) \\
\text { Initiations }_{i, t}\end{array}$ & $\begin{array}{c}\text { (3) } \\
\text { Suspensions }_{i, t}\end{array}$ & $\begin{array}{c}\text { (4) } \\
\text { Suspensions } i, t\end{array}$ \\
\hline Para IV $V_{i, t-1}$ & $\begin{array}{l}-0.676^{*} \\
(-1.855)\end{array}$ & $\begin{array}{l}-0.759 * * \\
(-2.075)\end{array}$ & $\begin{array}{l}0.833^{* *} \\
(2.135)\end{array}$ & $\begin{array}{l}0.872^{* *} \\
(2.139)\end{array}$ \\
\hline Para IV $V_{i, t-2}$ & $\begin{array}{l}-0.677^{* * *} \\
(-5.561)\end{array}$ & $\begin{array}{l}-0.722^{* * *} \\
(-6.092)\end{array}$ & $\begin{array}{l}0.618^{*} \\
(1.827)\end{array}$ & $\begin{array}{l}0.641^{*} \\
(1.844)\end{array}$ \\
\hline Avg Approval Prob $b_{i, t-1}$ & $\begin{array}{l}-0.004^{*} \\
(-1.813)\end{array}$ & $\begin{array}{c}-0.004 \\
(-1.554)\end{array}$ & $\begin{array}{l}-0.003^{*} \\
(-1.947)\end{array}$ & $\begin{array}{l}-0.003^{*} \\
(-1.926)\end{array}$ \\
\hline Indication Number ${ }_{i, t-1}$ & $\begin{array}{c}0.129 * * * \\
(7.285)\end{array}$ & $\begin{array}{c}0.129 * * * \\
(7.222)\end{array}$ & $\begin{array}{c}0.182^{* * *} \\
(6.697)\end{array}$ & $\begin{array}{c}0.182^{* * *} \\
(6.646)\end{array}$ \\
\hline $\log (T A)_{i, t}$ & & $\begin{array}{l}0.151^{* *} \\
(2.304)\end{array}$ & & $\begin{array}{c}-0.090 \\
(-1.581)\end{array}$ \\
\hline$E B I T / T A_{i, t-1}$ & & $\begin{array}{c}0.016 \\
(1.227)\end{array}$ & & $\begin{array}{c}-0.008 \\
(-1.010)\end{array}$ \\
\hline Cash $/ T A_{i, t-1}$ & & $\begin{array}{c}-0.089 \\
(-0.380)\end{array}$ & & $\begin{array}{l}0.337^{* *} \\
(2.530)\end{array}$ \\
\hline$R \mathcal{E D} / T A_{i, t-1}$ & & $\begin{array}{c}0.034 \\
(0.905)\end{array}$ & & $\begin{array}{c}-0.013 \\
(-0.593)\end{array}$ \\
\hline $\operatorname{Debt} / T A_{i, t-1}$ & & $\begin{array}{c}0.040 \\
(0.928)\end{array}$ & & $\begin{array}{c}-0.031 \\
(-1.085)\end{array}$ \\
\hline Firm FE & Yes & Yes & Yes & Yes \\
\hline Year FE & Yes & Yes & Yes & Yes \\
\hline $\mathrm{N}$ & 3,471 & 3,319 & 3,471 & 3,319 \\
\hline Adj. $R^{2}$ & 0.79 & 0.79 & 0.78 & 0.78 \\
\hline
\end{tabular}




\section{Table 4: Generic Entry and Innovation Activity, After FTC v. Actavis}

This table provides estimate results for innovation outcomes for equation (1) around the FTC $v$. Actavis ruling. Para $I V_{i, t}$ is the number of firm $i$ 's drugs affected by Paragraph IV entrants. Post is a dummy variable which takes a value of one if the year is 2013 or later. Initiations $i, t$ is the number of new drug trial initiations. Suspensions $s_{i, t}$ is the number of suspensions of drug trials. Pipeline controls include the lagged values of Avg Approval Prob and Indication Number. All controls additionally include $\log (T A)$, and the lagged values of EBIT/TA, Cash/TA, RED/TA, and Debt/TA. Regressions are run from 2005 to 2016. T-statistics are reported in parentheses, and robust standard errors are clustered at the firm level. A constant term (not reported) is included in all regressions. Firm and year fixed effects are included in all specifications, as indicated. ***, **, and * indicate significance at the $1 \%, 5 \%$, and $10 \%$ levels, respectively.

\begin{tabular}{lcccc}
\hline & $(1)$ & $(2)$ & $(3)$ & $(4)$ \\
Dependent Variable: & Initiations $_{i, t}$ & Initiations $i, t$ & Suspensions $_{i, t}$ & Suspensions $_{i, t}$ \\
\hline Para $I V_{i, t-1}$ & $-1.022^{* * *}$ & $-1.130^{* * *}$ & $0.910^{* *}$ & $0.964^{* *}$ \\
& $(-2.850)$ & $(-3.173)$ & $(2.238)$ & $(2.276)$ \\
Para $I V_{i, t-1} \times$ Post $_{t}$ & $2.196^{* * *}$ & $2.235^{* * *}$ & $-1.090^{*}$ & $-1.093^{*}$ \\
& $(3.801)$ & $(3.824)$ & $(-1.801)$ & $(-1.785)$ \\
Para $I V_{i, t-2}$ & $-0.622^{* * *}$ & $-0.672^{* * *}$ & $0.777^{* * *}$ & $0.805^{* * *}$ \\
& $(-3.587)$ & $(-3.929)$ & $(3.580)$ & $(3.603)$ \\
Para $I V_{i, t-2} \times$ Post $_{t}$ & $0.767^{*}$ & $0.784^{*}$ & $-1.230^{* * *}$ & $-1.215^{* * *}$ \\
& $(1.823)$ & $(1.827)$ & $(-2.759)$ & $(-2.698)$ \\
Controls & & & & All \\
Firm FE & Pipeline & All & Pipeline & Yes \\
Year FE & Yes & Yes & Yes & Yes \\
N & Yes & Yes & Yes & 3,319 \\
Adj. R & 3,471 & 3,319 & 3,471 & 0.79 \\
\hline
\end{tabular}




\section{Table 5: Exclusivity Loss Diff-in-Diff Regressions: Project Initiations and Suspensions}

This table provides estimate results for innovation outcomes for equation (2). Panel A provides results at the firm-year level, while Panel B provides results at the firm-ICD-year level. ExcluLoss2013-2016 is a dummy variable that takes a value of one if the firm or firm-ICD has a drug with exclusivity expiring from 2013 to 2016, and zero otherwise. Post is a dummy variable that takes a value of one if the year is 2013 or later. Initiations is the number of new drug trial initiations. Suspensions is the number of suspensions of drug trials. Pipeline controls include the lagged values of Avg Approval Prob and Indication Number. All controls additionally include $\log (T A)$, and the lagged values of EBIT/TA, Cash/TA, RED/TA, and Debt/TA. Firm-ICD controls include the lagged number of drugs in each phase in a firm's specific ICD category, as well as the lagged average probability of success for that ICD category. Regressions are run from 2005 to 2016. T-statistics are reported in parentheses, and robust standard errors are clustered at the firm level. A constant term (not reported) is included in all regressions. Fixed effects are included in all specifications, as indicated. ${ }^{* * *},{ }^{* *}$, and ${ }^{*}$ indicate significance at the $1 \%, 5 \%$, and $10 \%$ levels, respectively.

Panel A: Firm-year Level

\begin{tabular}{lcccc}
\hline & $(1)$ & $(2)$ & $(3)$ & $(4)$ \\
& Initiations $_{i, t}$ & Initiations $_{i, t}$ & Suspensions $_{i, t}$ & Suspensions $_{i, t}$ \\
\hline ExcluLoss2013-2016 ${ }_{i} \times$ Post $_{t}$ & $2.338^{* * *}$ & $2.470^{* * *}$ & $-1.616^{* * *}$ & $-1.617^{* * *}$ \\
& $(3.138)$ & $(3.167)$ & $(-3.025)$ & $(-2.872)$ \\
& & & & \\
Controls & Pipeline & All & Pipeline & All \\
Firm FE & Yes & Yes & Yes & Yes \\
Year FE & Yes & Yes & Yes & Yes \\
N & 3,835 & 3,549 & 3,835 & 3,549 \\
Adj. R ${ }^{2}$ & 0.78 & 0.78 & 0.77 & 0.77 \\
\hline
\end{tabular}

Panel B: Firm-ICD-year Level

\begin{tabular}{lcccccc}
\hline & $(1)$ & $(2)$ & $(3)$ & $(4)$ & $(5)$ & $(6)$ \\
& Initiations $_{i j, t}$ & Suspensions $_{i, j, t}$ & Initiations $i j, t^{*}$ & Suspensions $_{i, j, t}$ & Initiations $_{i, j, t}$ & Suspensions $_{i, j}$ \\
\hline $\begin{array}{l}\text { ExcluLoss2013-2016 } i, j \\
\times \text { Post }_{t}\end{array}$ & $0.119^{*}$ & $-0.076^{*}$ & $0.129^{*}$ & $-0.110^{* *}$ & $0.124^{*}$ & $-0.148^{* * *}$ \\
& $(1.711)$ & $(-1.749)$ & $(1.889)$ & $(-2.415)$ & $(1.793)$ & $(-3.044)$ \\
Firm-ICD Controls & $\mathrm{Y}$ & $\mathrm{Y}$ & $\mathrm{Y}$ & $\mathrm{Y}$ & $\mathrm{Y}$ & $\mathrm{Y}$ \\
Firm-ICD FE & $\mathrm{Y}$ & $\mathrm{Y}$ & $\mathrm{N}$ & $\mathrm{N}$ & $\mathrm{N}$ & $\mathrm{N}$ \\
Year FE & $\mathrm{Y}$ & $\mathrm{Y}$ & $\mathrm{N}$ & $\mathrm{N}$ & $\mathrm{N}$ & $\mathrm{N}$ \\
Firm FE & $\mathrm{N}$ & $\mathrm{N}$ & $\mathrm{Y}$ & $\mathrm{Y}$ & $\mathrm{N}$ & $\mathrm{N}$ \\
Category-Year FE & $\mathrm{N}$ & $\mathrm{N}$ & $\mathrm{Y}$ & $\mathrm{Y}$ & $\mathrm{N}$ & $\mathrm{N}$ \\
Category FE & $\mathrm{N}$ & $\mathrm{N}$ & $\mathrm{N}$ & $\mathrm{N}$ & $\mathrm{Y}$ & $\mathrm{Y}$ \\
Firm-Year FE & $\mathrm{N}$ & $\mathrm{N}$ & $\mathrm{N}$ & $\mathrm{N}$ & $\mathrm{Y}$ & $\mathrm{Y}$ \\
N & 23,781 & 23,781 & 25,252 & 25,252 & 24,666 & 24,666 \\
Adj. R-sq & 0.28 & 0.31 & 0.31 & 0.34 & 0.41 & 0.32 \\
\hline
\end{tabular}




\section{Table 6: Exclusivity Loss Diff-in-Diff Regressions: Innovation Value}

This table provides estimate results for innovation value outcomes for equation (2). ExcluLoss2013-2016 is a dummy variable that takes a value of one if the firm has a drug with exclusivity expiring from 2013 to 2016, and zero otherwise. Post is a dummy variable that takes a value of one if the year is 2013 or later. PatentValue is the total economic value of patents issued by a given firm. Pipeline controls include the lagged values of Avg Approval Prob and Indication Number. All controls additionally include $\log (T A)$, and the lagged values of EBIT/TA, Cash/TA, $R \mathcal{E D} / T A$, and Debt/TA. Regressions are run from 2005 to 2016. T-statistics are reported in parentheses, and robust standard errors are clustered at the firm level. A constant term (not reported) is included in all regressions. Fixed effects are included in all specifications, as indicated. ${ }^{* * *},{ }^{* *}$, and ${ }^{*}$ indicate significance at the $1 \%, 5 \%$, and $10 \%$ levels, respectively.

\begin{tabular}{lcc}
\hline & $(1)$ & $(2)$ \\
& PatentValue $_{i, t}$ & PatentValue $_{i, t}$ \\
\hline ExcluLoss2013-2016 ${ }_{i} \times$ Post $_{t}$ & $348.848^{* *}$ & $283.289^{* *}$ \\
& $(2.416)$ & $(2.229)$ \\
Controls & & \\
Firm FE & Pipeline & All \\
Year FE & Yes & Yes \\
N & Yes & Yes \\
Adj. R $^{2}$ & 3,835 & 3,549 \\
\hline
\end{tabular}




\section{Table 7: Exclusivity Loss and Sales}

This table provides estimate results for innovation outcomes for equation (2), but it splits the treatment according to exclusivity loss and sales. ExcluLoss2013-2016 $i$ is a dummy variable that takes a value of one if the firm has a drug with exclusivity expiring from 2013 to 2016, and zero otherwise. Post is a dummy variable that takes a value of one if the year is 2013 or later. HSale takes a value of 1 if company's exclusivity-expiring drug is in the top 100 sales (blockbuster drugs). LSale $e_{i}$ takes a value of 1 if company's exclusivity-expiring drug is not the in top 100 sales. $\mathrm{HNum}_{i}$ takes a value of 1 if company is above-median in terms of number of exclusivity-expiring drugs. $\mathrm{LNum}_{i}$ takes a value of 1 if company is below-median in terms of number of exclusivityexpiring drugs. Initiations $s_{i, t}$ is the number of new drug trial initiations. Suspensions $s_{i, t}$ is the number of suspensions of drug trials. PatentValue is the total economic value of patents issued by a given firm. Pipeline controls include the lagged values of Avg Approval Prob and Indication Number. All controls additionally include $\log (T A)$, and the lagged values of EBIT/TA, Cash/TA, RED/TA, and Debt/TA. Regressions are run from 2005 to 2016. T-statistics are reported in parentheses, and robust standard errors are clustered at the firm level. A constant term (not reported) is included in all regressions. Firm and year fixed effects are included in all specifications, as indicated. ${ }^{* * *}$, **, and * indicate significance at the $1 \%, 5 \%$, and $10 \%$ levels, respectively.

\begin{tabular}{|c|c|c|c|c|c|c|}
\hline & $\begin{array}{c}(1) \\
\text { Initiations }_{i, t}\end{array}$ & $\begin{array}{c}\text { (2) } \\
\text { Suspensions }_{i, t}\end{array}$ & $\begin{array}{c}\text { (3) } \\
\text { PatentValue }{ }_{i, t}\end{array}$ & $\begin{array}{c}(4) \\
\text { Initiations }_{i, t}\end{array}$ & $\begin{array}{c}(5) \\
\text { Suspensions }_{i, t}\end{array}$ & $\begin{array}{c}(6) \\
\text { PatentValue }{ }_{i, t}\end{array}$ \\
\hline ExcluLoss2013-2016 $\times$ & $5.483^{* * *}$ & $-3.583^{* * *}$ & $629.100^{* *}$ & & & \\
\hline Post $_{t} \times$ HSale $_{i}$ & $(3.586)$ & $(-3.016)$ & (1.997) & & & \\
\hline ExcluLoss2013-2016 $\times$ & 0.396 & -0.402 & 166.081 & & & \\
\hline Post $_{t} \times$ LSale $_{i}$ & $(0.684)$ & $(-1.042)$ & $(1.426)$ & & & \\
\hline ExcluLoss2013-2016 $\times$ & & & & $5.135^{* * *}$ & $-3.097 * * *$ & $463.910^{*}$ \\
\hline Post $_{t} \times \mathrm{HNum}_{i}$ & & & & $(3.640)$ & $(-2.837)$ & (1.923) \\
\hline ExcluLoss2013-2016 $\times$ & & & & 0.065 & -0.281 & 236.263 \\
\hline Post $_{t} \times \mathrm{LNum}_{i}$ & & & & $(0.199)$ & $(-1.153)$ & (1.518) \\
\hline Controls & All & All & All & All & All & All \\
\hline Firm FE & Yes & Yes & Yes & Yes & Yes & Yes \\
\hline Year FE & Yes & Yes & Yes & Yes & Yes & Yes \\
\hline $\mathrm{N}$ & 3,835 & 3,835 & 3,835 & 3,835 & 3,835 & 3,835 \\
\hline Adj. $R^{2}$ & 0.79 & 0.78 & 0.83 & 0.79 & 0.78 & 0.83 \\
\hline
\end{tabular}




\section{Table 8: The Effects of Exclusivity Loss on Additional Outcome Variables}

This table provides estimate results for acquisition, R\&D and financial outcomes for equation (2). ExcluLoss2013-2016 is a dummy variable that takes a value of one if the firm has a drug with exclusivity expiring from 2013 to 2016, and zero otherwise. Post is a dummy variable that takes a value of one if the year is 2013 or later. Para $I V_{i, t}$ is the number of firm $i$ 's drugs affected by Paragraph IV entrants. DrugAcq $q_{i, t}$ is the number of acquisitions of drugs from other companies. EarlyDrugAcq $q_{i, t}$ is the number of acquisitions of drugs in preclinical or Phase I from other companies. The financial include R\&D expenditures $R \mathcal{E D} / T A$, cash holdings Cash/TA, and leverage ratio Debt/TA. Pipeline controls include the lagged values of Avg Approval Prob and Indication Number. All controls additionally include $\log (\mathrm{T} A)$, and the lagged values of EBIT/TA, Cash/TA, RED/TA, and Debt/TA. Regressions are run from 2005 to 2016. T-statistics are reported in parentheses, and robust standard errors are clustered at the firm level. A constant term (not reported) is included in all regressions. Firm and year fixed effects are included in all specifications, as indicated. ${ }^{* *},{ }^{* *}$, and ${ }^{*}$ indicate significance at the $1 \%, 5 \%$, and $10 \%$ levels, respectively.

\begin{tabular}{lccccc}
\hline & $(1)$ & $(2)$ & $(3)$ & $(4)$ & $(5)$ \\
& DrugAcq $_{i, t}$ & EarlyDrugAcq $_{i, t}$ & R\&D/TA $A_{i, t}$ & ${\text { Cash } / T A_{i, t}}^{\text {Debt } / T A_{i, t}}$ \\
\hline ExcluLoss2013-2016 $\times$ & $0.274^{* *}$ & $0.086^{*}$ & $0.249^{* * *}$ & $-0.067^{* * *}$ & $0.137^{* *}$ \\
Post $_{t}$ & $(2.089)$ & $(1.796)$ & $(2.696)$ & $(-3.437)$ & $(2.160)$ \\
& & & & \\
Controls & All & All & All & All & All \\
Firm FE & Yes & Yes & Yes & Yes & Yes \\
Year FE & Yes & Yes & Yes & Yes & Yes \\
N & 3,549 & 3,549 & 3,542 & 3,549 & 3,535 \\
Adj. $\mathrm{R}^{2}$ & 0.10 & 0.04 & 0.48 & 0.70 & 0.61 \\
\hline
\end{tabular}




\section{Table 9: Effect on Litigation Outcomes}

This table provides the results of litigation outcomes for equation (2). ExcluLoss2013-2016 is a dummy variable that takes a value of one if the firm has a drug with exclusivity expiring from 2013 to 2016, and zero otherwise. Post is a dummy variable that takes a value of one if the year is 2013 or later. Para $I V_{i, t}$ is the number of firm i's drugs affected by Paragraph IV entrants. Settlement $t_{i, t}$ is the number of projects for which there are settlements. CourtNumit, is the number of cases which end up with a court ruling. EntryRuling $g_{i, t}$ is the number of cases where the generic drug is allowed to enter the market. Pipeline controls include the lagged values of Avg Approval Prob and Indication Number. All controls additionally include $\log (\mathrm{TA})$, and the lagged values of EBIT/TA, Cash/TA, RED/TA, and Debt/TA. Regressions are run from 2005 to 2016. T-statistics are reported in parentheses, and robust standard errors are clustered at the firm level. A constant term (not reported) is included in all regressions. Firm and year fixed effects are included in all specifications, as indicated. ${ }^{* *},{ }^{* *}$, and * indicate significance at the $1 \%, 5 \%$, and $10 \%$ levels, respectively.

\begin{tabular}{lccc}
\hline & $(1)$ & $(2)$ & $(3)$ \\
& Settlement $_{, t}$ & CourtNum $_{i, t}$ & EntryRuling $_{i, t}$ \\
\hline ExcluLoss2013-2016 C Post $_{t}$ & -0.185 & $0.182^{* *}$ & $0.087^{* *}$ \\
& $(-1.231)$ & $(2.569)$ & $(2.312)$ \\
Controls & & & \\
Firm FE & All & All & All \\
Year FE & Yes & Yes & Yes \\
N & Yes & Yes & Yes \\
Adj. R & 3,549 & 3,549 & 3,549 \\
\hline
\end{tabular}




\section{Table 10: Overall Effect on Innovation by Therapeutic Area}

This table shows results at the therapeutic category level $j$. ExcluLoss2013-2016 $6_{j}$ takes a value of 1 if the area $j$ has at least one approved product losing its marketing exclusivity between 2013 and 2016, and 0 otherwise. Post is a dummy variable that takes a value of 1 if the year is 2013 or later, and 0 otherwise. Suspensions $s_{j, t}$ is the number of suspensions of drug trials in area $j$. DrugAcq $q_{j, t}$ is the number of acquisitions of drugs from other companies in area $j$. Initiation $s_{j, t}$ is the total number of new drug trial initiations in area $j$. IncInitiation $n_{j, t}$ and EntInitiation ${ }_{j, t}$ are the numbers of initiations by incumbents and new entrants, respectively. Entrants ${ }_{j, t}$ is the number of firms entering into therapeutic area $j$. Regressions are run from 2005 to 2016. T-statistics are reported in parentheses, and robust standard errors are clustered at the therapeutic area level. A constant term (not reported) is included in all regressions. Therapeutic area and year fixed effects are included in all specifications, as indicated. ${ }^{* * *},{ }^{* *}$, and ${ }^{*}$ indicate significance at the $1 \%, 5 \%$, and $10 \%$ levels, respectively.

\begin{tabular}{|c|c|c|c|c|c|c|}
\hline & $\begin{array}{c}(1) \\
\text { Suspensions }_{j, t}\end{array}$ & $\begin{array}{c}(2) \\
\text { DrugAcq } q_{j, t} \\
\end{array}$ & $\begin{array}{c}(3) \\
\text { Initiations }_{j, t} \\
\end{array}$ & $\begin{array}{c}(4) \\
\text { EntInitiation }_{j, t}\end{array}$ & $\begin{array}{c}(5) \\
\text { IncInitiation }_{j, t}\end{array}$ & $\begin{array}{c}(6) \\
\text { Entrants }_{j, t}\end{array}$ \\
\hline ExcluLoss2013- & $-1.297^{* * *}$ & $0.772^{*}$ & 0.496 & $-1.197^{* * *}$ & $1.694^{* * *}$ & $-1.183^{* * *}$ \\
\hline $2016_{j} \times$ Post $_{t}$ & $(-2.734)$ & (1.890) & $(0.953)$ & $(-4.244)$ & $(2.964)$ & $(-4.493)$ \\
\hline NumDrugs $_{j, t-1}$ & $\begin{array}{c}0.158^{* * *} \\
(4.288)\end{array}$ & $\begin{array}{l}0.027^{*} \\
(1.689)\end{array}$ & $\begin{array}{c}0.056 \\
(1.051)\end{array}$ & $\begin{array}{c}0.001 \\
(0.035)\end{array}$ & $\begin{array}{c}0.055 \\
(0.760)\end{array}$ & $\begin{array}{c}-0.001 \\
(-0.056)\end{array}$ \\
\hline$A v g A p p P r o b_{j, t-1}$ & $\begin{array}{c}-0.004 \\
(-0.573)\end{array}$ & $\begin{array}{c}-0.002 \\
(-0.580)\end{array}$ & $\begin{array}{c}-0.026^{* * *} \\
(-3.564)\end{array}$ & $\begin{array}{c}0.008 \\
(0.967)\end{array}$ & $\begin{array}{c}-0.034^{* * *} \\
(-3.221)\end{array}$ & $\begin{array}{c}0.011 \\
(1.478)\end{array}$ \\
\hline NumFirms $_{j, t-1}$ & $\begin{array}{l}-0.104^{* *} \\
(-2.091)\end{array}$ & $\begin{array}{c}0.010 \\
(0.474)\end{array}$ & $\begin{array}{c}0.102 \\
(1.516)\end{array}$ & $\begin{array}{c}-0.034 \\
(-1.029)\end{array}$ & $\begin{array}{c}0.137 \\
(1.574)\end{array}$ & $\begin{array}{l}-0.056^{*} \\
(-1.690)\end{array}$ \\
\hline Category FE & Yes & Yes & Yes & Yes & Yes & Yes \\
\hline Year FE & Yes & Yes & Yes & Yes & Yes & Yes \\
\hline $\mathrm{N}$ & 1,649 & 1,649 & 1,649 & 1,649 & 1,649 & 1,649 \\
\hline Adj. $R^{2}$ & 0.82 & 0.33 & 0.84 & 0.64 & 0.62 & 0.63 \\
\hline
\end{tabular}




\section{Appendix}

\section{Table A1: Robustness - Placebo Test}

This table provides estimate results for innovation outcomes for equation (2) at the firm level. ExcluLoss2009-2012 is a dummy variable that takes a value of one if the firm or firm-ICD has a drug with exclusivity expiring from 2009 to 2012, and zero otherwise. PseudoPost is a dummy variable that takes a value of one if the year is $\mathbf{2 0 0 9}$ or later. Initiations is the number of new drug trial initiations. Suspensions is the number of suspensions of drug trials. PatentValue is the total economic value of patents issued by a given firm. Pipeline controls include the lagged values of Avg Approval Prob and Indication Number. All controls additionally include $\log (T A)$, and the lagged values of EBIT/TA, Cash/TA, RED/TA, and Debt/TA. Firm-ICD controls include the lagged number of drugs in each phase in a firm's specific ICD category, as well as the lagged average probability of success for that ICD category. Regressions are run from 2005 to 2012. T-statistics are reported in parentheses, and robust standard errors are clustered at the firm level. A constant term (not reported) is included in all regressions. Fixed effects are included in all specifications, as indicated. ${ }^{* * *},{ }^{* *}$, and ${ }^{*}$ indicate significance at the $1 \%, 5 \%$, and $10 \%$ levels, respectively.

\begin{tabular}{lcccccc}
\hline & $(1)$ & $(2)$ & $(3)$ & $(4)$ & $(5)$ & $(6)$ \\
& Initiations $_{i, t}$ & Initiations $_{i, t}$ & Suspensions $_{i, t}$ & Suspensions $_{i, t}$ & PatentValue $_{i, t}$ & PatentValue $_{i, t}$ \\
\hline ExcluLoss2009-2012 $2_{i} \times$ & 0.511 & 0.362 & 0.508 & 0.598 & 10.571 & -7.485 \\
PseudoPost $_{t}$ & $(1.019)$ & $(0.695)$ & $(1.248)$ & $(1.400)$ & $(0.217)$ & $(-0.150)$ \\
& & & & & & \\
Controls & & & & & & \\
Firm FE & Pipeline & All & Pipeline & All & Pipeline & All \\
Year FE & Yes & Yes & Yes & Yes & Yes & Yes \\
N & Yes & Yes & Yes & Yes & Yes & Yes \\
Adj. R & 2003 & 1806 & 2003 & 1806 & 2003 & 1806 \\
\hline & 0.80 & 0.80 & 0.80 & 0.80 & 0.91 & 0.91 \\
\hline
\end{tabular}




\section{Table A2: Robustness -Generic Entry, Cash Constraints, and Innovation Activity}

This table provides estimate results for innovation outcomes for equation (1) around the FTC $v$. Actavis ruling, also examining the effect of cash constraints. Para $I V_{i, t}$ is the number of firm $i$ 's drugs affected by Paragraph IV entrants. Post is a dummy variable that takes a value of one if the year is 2013 or later. Initiations $i_{i, t}$ is the number of new drug trial initiations. Suspensions $i, t$ is the number of suspensions of drug trials. $L$ Cash $i, t$ that takes a value of 1 if firm $i$ 's cash scaled by total assets is below the median level for all firms in year $t$, and 0 otherwise. Pipeline controls include the lagged values of Avg Approval Prob and Indication Number. All controls additionally include $\log (\mathrm{TA})$, and the lagged values of EBIT/TA, Cash/TA, RED/TA, and Debt/TA. Regressions are run from 2005 to 2016. T-statistics are reported in parentheses, and robust standard errors are clustered at the firm level. A constant term (not reported) is included in all regressions. Firm and year fixed effects are included in all specifications, as indicated. ${ }^{* * *},{ }^{* *}$, and * indicate significance at the $1 \%, 5 \%$, and $10 \%$ levels, respectively.

\begin{tabular}{|c|c|c|c|c|}
\hline & $\begin{array}{c}(1) \\
\text { Initiations }_{i, t}\end{array}$ & $\begin{array}{c}(2) \\
\text { Initiations }_{i, t}\end{array}$ & $\begin{array}{c}\text { (3) } \\
\text { Suspensions }_{i, t}\end{array}$ & $\begin{array}{c}(4) \\
\text { Suspensions }_{i, t}\end{array}$ \\
\hline Para IV $V_{i, t-1} \times$ Post $_{t}$ & & $\begin{array}{c}2.262^{* * *} \\
(3.860)\end{array}$ & & $\begin{array}{l}-1.085^{*} \\
(-1.755)\end{array}$ \\
\hline Para $I V_{i, t-1}$ & $\begin{array}{c}-2.384 \\
(-1.518)\end{array}$ & $\begin{array}{l}-3.334^{* *} \\
(-2.003)\end{array}$ & $\begin{array}{c}0.779 \\
(0.740)\end{array}$ & $\begin{array}{c}1.122 \\
(0.922)\end{array}$ \\
\hline Para IV $_{i, t-1} \times$ LCash $_{i, t-1}$ & $\begin{array}{c}1.651 \\
(0.989)\end{array}$ & $\begin{array}{c}2.234 \\
(1.304)\end{array}$ & $\begin{array}{c}0.102 \\
(0.089)\end{array}$ & $\begin{array}{c}-0.156 \\
(-0.128)\end{array}$ \\
\hline Para IV $V_{i, t-2} \times$ Post $_{t}$ & & $\begin{array}{l}0.784^{*} \\
(1.794)\end{array}$ & & $\begin{array}{c}-1.231^{* * *} \\
(-2.716)\end{array}$ \\
\hline Para $I V_{i, t-2}$ & $\begin{array}{l}-1.819 * * \\
(-2.369)\end{array}$ & $\begin{array}{l}-2.012^{* *} \\
(-2.458)\end{array}$ & $\begin{array}{c}1.882 \\
(0.957)\end{array}$ & $\begin{array}{c}2.412 \\
(1.230)\end{array}$ \\
\hline Para IV $V_{i, t-2} \times L_{\text {Cash }}$ Cat -2 & $\begin{array}{l}1.120 \\
(1.413)\end{array}$ & $\begin{array}{c}1.372 \\
(1.630)\end{array}$ & $\begin{array}{c}-1.261 \\
(-0.636)\end{array}$ & $\begin{array}{c}-1.631 \\
(-0.829)\end{array}$ \\
\hline $\operatorname{LCash}_{i, t-1}$ & $\begin{array}{c}-0.088 \\
(-0.632)\end{array}$ & $\begin{array}{c}0.066 \\
(0.506)\end{array}$ & $\begin{array}{c}0.160 \\
(1.450)\end{array}$ & $\begin{array}{c}0.042 \\
(0.414)\end{array}$ \\
\hline LCash $_{i, t-2}$ & $\begin{array}{c}-0.029 \\
(-0.225)\end{array}$ & $\begin{array}{c}-0.020 \\
(-0.154)\end{array}$ & $\begin{array}{c}-0.009 \\
(-0.145)\end{array}$ & $\begin{array}{c}-0.017 \\
(-0.275)\end{array}$ \\
\hline Controls & All & All & All & All \\
\hline Firm FE & Y & Y & Y & Y \\
\hline Year FE & Y & Y & Y & Y \\
\hline $\mathrm{N}$ & 3,196 & 3,196 & 3,196 & 3,196 \\
\hline Adj. R-sq & 0.79 & 0.81 & 0.78 & 0.79 \\
\hline
\end{tabular}




\section{Table A3: Robustness - IV Regressions for Generic Entry and Innovation Activity}

This table provides instrumental variable (IV) estimation results for innovation outcomes. Para $I V_{i, t}$ is the number of firm $i$ 's drugs affected by Paragraph IV entrants. Post is a dummy variable that takes a value of one if the year is 2013 or later. ExcluLossNum is the number of drugs facing a loss of exclusivity post-ruling. Initiations $s_{i, t}$ is the number of new drug trial initiations. Suspensions $i_{i, t}$ is the number of suspensions of drug trials. Pipeline controls include the lagged values of Avg Approval Prob and Indication Number. All controls additionally include $\log (\mathrm{TA})$, and the lagged values of EBIT/TA, Cash/TA, RED/TA, and Debt/TA. Regressions are run from 2005 to 2016. Tstatistics are reported in parentheses, and robust standard errors are clustered at the firm level. A constant term (not reported) is included in all regressions. Firm and year fixed effects are included in all specifications, as indicated. ${ }^{* *},{ }^{* *}$, and ${ }^{*}$ indicate significance at the $1 \%, 5 \%$, and $10 \%$ levels, respectively.

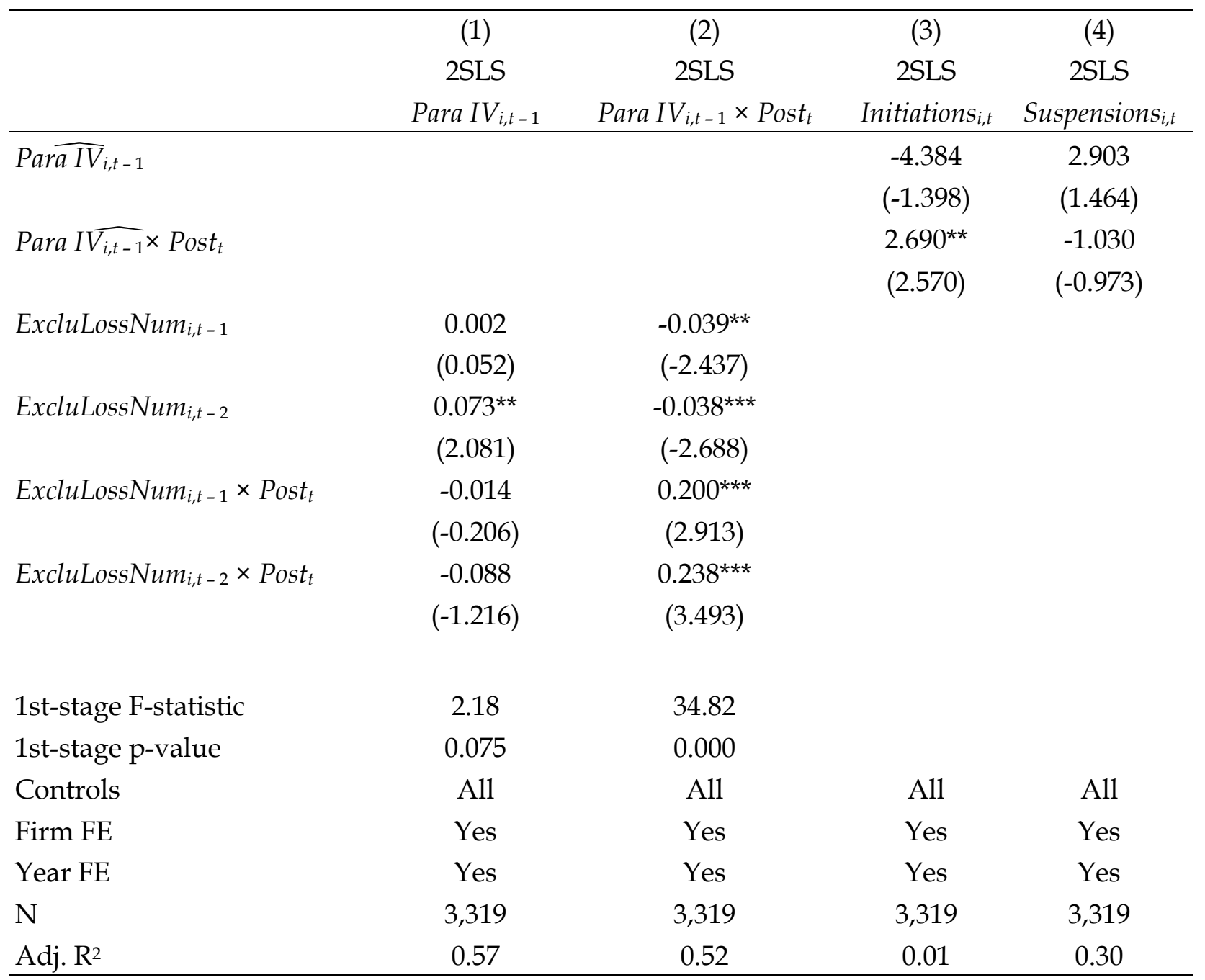




\section{Table A4: IV Regressions for Generic Entry and Innovation Activity, 2-year Lags}

This table provides instrumental variable (IV) estimation results for innovation outcomes. Para $I V_{i, t}$ is the number of firm $i$ 's drugs affected by Paragraph IV entrants. Post is a dummy variable that takes a value of one if the year is 2013 or later. ExcluLossNum is the number of drugs facing a loss of exclusivity post-ruling. Initiations $s_{i, t}$ is the number of new drug trial initiations. Suspensions $i_{i, t}$ is the number of suspensions of drug trials. Pipeline controls include the lagged values of $A v g$ Approval Prob and Indication Number. All controls additionally include $\log (\mathrm{TA})$, and the lagged values of EBIT/TA, Cash/TA, RED/TA, and Debt/TA, besides the pipeline controls. Regressions are run from 2005 to 2016 . T-statistics are reported in parentheses, and robust standard errors are clustered at the firm level. A constant term (not reported) is included in all regressions. Firm and year fixed effects are included in all specifications, as indicated. ${ }^{* * *},{ }^{* *}$, and ${ }^{*}$ indicate significance at the $1 \%, 5 \%$, and $10 \%$ levels, respectively.

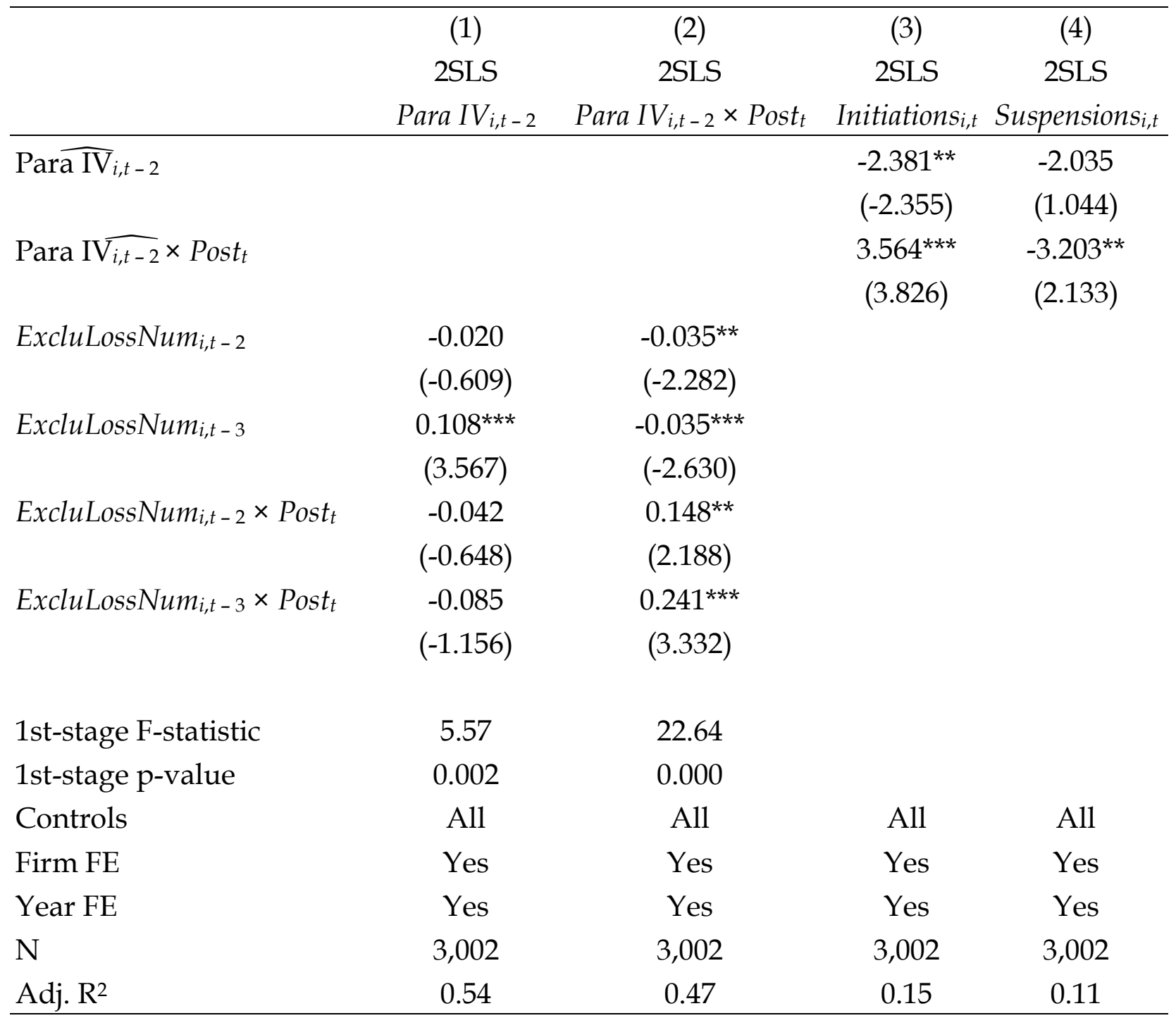

